\title{
Antiviral and Antioxidant Activity of a Hydroalcoholic Extract from Humulus lupulus L.
}

\author{
Antonella Di Sotto DD, $^{1}$ Paola Checconi $\left(\mathbb{D},{ }^{2,3}\right.$ Ignacio Celestino, ${ }^{2,3}$ Marcello Locatelli, ${ }^{4}$ \\ Stefania Carissimi, ${ }^{5}$ Marta De Angelis, ${ }^{2}$ Valeria Rossi, ${ }^{2}$ Dolores Limongi, ${ }^{3}$ Chiara Toniolo (D), \\ Lucia Martinoli, ${ }^{1}$ Silvia Di Giacomo, ${ }^{1}$ Anna Teresa Palamara $\mathbb{D}^{2,3}$ and Lucia Nencioni $\mathbb{D}^{2}$ \\ ${ }^{1}$ Department of Physiology and Pharmacology V. Erspamer, Sapienza University of Rome, P.le Aldo Moro 5, 00185 Rome, Italy \\ ${ }^{2}$ Department of Public Health and Infectious Diseases, Laboratory Affiliated to Istituto Pasteur Italia-Fondazione Cenci Bolognetti, \\ Sapienza University of Rome, P.le Aldo Moro 5, 00185 Rome, Italy \\ ${ }^{3}$ IRCCS San Raffaele Pisana, Department of Human Sciences and Promotion of the Quality of Life, San Raffaele Roma Open \\ University, Via di Val Cannuta 247, 00166 Rome, Italy \\ ${ }^{4}$ Department of Pharmacy, University “G. D’Annunzio" of Chieti-Pescara, Via dei Vestini 31, 66100 Chieti, Italy \\ ${ }^{5}$ Department of Biochemical Sciences "A. Rossi Fanelli”, Sapienza University of Rome, P.le Aldo Moro 5, 00185 Rome, Italy \\ ${ }^{6}$ Department of Environmental Biology, Sapienza University of Rome, P.le Aldo Moro 5, 00185 Rome, Italy
}

Correspondence should be addressed to Antonella Di Sotto; antonella.disotto@uniroma1.it and Paola Checconi; paola.checconi@uniroma1.it

Received 10 January 2018; Accepted 16 May 2018; Published 24 July 2018

Academic Editor: Ralf Hausmann

Copyright ( 2018 Antonella Di Sotto et al. This is an open access article distributed under the Creative Commons Attribution License, which permits unrestricted use, distribution, and reproduction in any medium, provided the original work is properly cited.

\begin{abstract}
A hydroalcoholic extract from female inflorescences of Humulus lupulus L. (HOP extract) was evaluated for its anti-influenza activity. The ability of the extract to interfere with different phases of viral replication was assessed, as well as its effect on the intracellular redox state, being unbalanced versus the oxidative state in infected cells. The radical scavenging power, inhibition of lipoperoxidation, and ferric reducing activity were assayed as antioxidant mechanisms. A phytochemical characterization of the extract was also performed. We found that HOP extract significantly inhibited replication of various viral strains, at different time from infection. Viral replication was partly inhibited when virus was incubated with extract before infection, suggesting a direct effect on the virions. Since HOP extract was able to restore the reducing conditions of infected cells, by increasing glutathione content, its antiviral activity might be also due to an interference with redox-sensitive pathways required for viral replication. Accordingly, the extract exerted radical scavenging and reducing effects and inhibited lipoperoxidation and the tBOOH-induced cytotoxicity. At phytochemical analysis, different phenolics were identified, which altogether might contribute to HOP antiviral effect. In conclusion, our results highlighted anti-influenza and antioxidant properties of HOP extract, which encourage further in vivo studies to evaluate its possible application.
\end{abstract}

\section{Introduction}

Nowadays, influenza remains one of the main causes of morbidity worldwide, with seasonal epidemics and periodic pandemics. The disease is caused by an enveloped, RNA virus, which infects mainly the upper airways, but complications at lower respiratory tract can occur, especially in children and elderly [1].
Although different strategies have been approached to prevent the disease and/or manage its complications, the only anti-influenza drugs approved by FDA belong to two classes of inhibitors, which target the viral matrix protein 2 and neuraminidase [2]. Unfortunately, their efficacy is often limited by toxicity and by the emergence of novel drug-resistant viral mutants, thus requiring alternative and more effective therapeutic strategies [3]. Research in the field is looking for 
alternative molecules, both of natural and synthesis origin that could interfere with different targets, including cell host structures and pathways that virus exploits for its replication, and reduce the probability of drug resistance [4-6].

Several intracellular pathways that influenza virus activates are redox-sensitive $[7,8]$, and interestingly, some antioxidant molecules, including polyphenols, that are able to modulate the intracellular redox balance, also show antiinfluenza activity [9-11]. Natural polyphenolic compounds, proanthocyanidins and catechins, have been found to possess antiviral properties, particularly against influenza A [12-14].

Female strobilus inflorescences (hops or cones) of Humulus lupulus L. (Fam. Cannabaceae) are widely used in the brewing industry as preservative and flavouring additives; in fact, $H$. lupulus is considered as an essential ingredient in beer, contributing to the bitter flavour and the characteristic hoppy aroma and providing preservative and antimicrobial effects [15-18]. Beer is often considered to be a "functional beverage" as a source of health-promoting substances [19]. Among them, polyphenolic compounds, mainly prenylflavonoids and procyanidins, along with chalcones (namely, xanthohumol) and the phytoestrogen 8-prenylnaringenin, have gained the most attention $[17,20]$. Furthermore, $H$. lupulus extracts are used in traditional medicine as bitter stomachic and as remedies for mild sleeping disorders, in combination with other sedative herbs such as valerian, passion flower, and lemon balm [21].

$H$. lupulus and its polyphenolic constituents are reported to possess other interesting biological properties, including antimicrobial, antioxidant, anti-inflammatory, and chemopreventive activities [22-24]. Although antimicrobial (antibacterial and antifungal) properties are well known, little is reported about the antiviral activity of crude hop extracts and their purified components. Buckwold et al. [25] found that iso- $\alpha$-acids and xanthohumol have a moderate antiviral activity against different RNA and DNA viruses, thus suggesting their possible role as lead compounds for more active antiviral agents.

In line with this evidence and our preliminary results [26], in the present study, the anti-influenza activity of a hydroalcoholic extract from the female inflorescences of $H$. lupulus (HOP extract) was evaluated. The ability of HOP to interfere with specific steps of viral replication was shown using an in vitro model, represented by permissive epithelial cell lines infected with different influenza A virus strains.

The HOP extract was characterized for its phenolic composition by both high-performance thin-layer chromatography (HPTLC) and high-performance liquid chromatography (HPLC-PDA), and the total polyphenol, tannin, and flavonoid amount was determined colorimetrically. Finally, the radical scavenger ability, the crocin bleaching activity, the inhibition of lipoperoxidation, and the iron reducing activity were evaluated as possible antioxidant and cytoprotective mechanisms of the HOP extract.

\section{Materials and Methods}

2.1. HOP Extract. A hydroalcoholic extract from the female inflorescences of $H$. lupulus L. (HOP extract; batch $\mathrm{n}$.
1101385; code n. 3120004; ratio drug/extract 4:1), kindly supplied by EPO S.r.l. (Milan, Italy), was used to perform the experiments. The extract was standardized to contain $0.4 \%$ of flavonoids, determined as rutin equivalents.

2.2. Chemicals. All the chemicals, including 3-(4,5-dimethylthiazol-2-yl)-2,5-diphenyltetrazolium bromide (MTT; $98 \%$ purity), tert-butyl hydroperoxide $(\mathrm{tBOOH}, 70 \%$ wt in $\mathrm{H}_{2} \mathrm{O}$ ), Triton X-100, 1,1-diphenyl-2-picryl-hydrazyl (DPPH; 95\% purity), 2,2'-azino-bis(3-thylbenzothiazoline-6-sulfonic acid) diammonium salt (ABTS; 98\% purity), 2,2' -azobis (2methylpropionamidine) dihydrochloride (AAPH; $97 \%$ purity), ferrozine (97\% purity), hydroxylamine hydrochloride (98\% purity), iron(III) chloride $\left(\mathrm{FeCl}_{3} \times 6 \mathrm{H}_{2} \mathrm{O} ; 97 \%\right.$ purity), iron(II) sulfate heptahydrate $\left(\mathrm{FeSO}_{4} \times 7 \mathrm{H}_{2} \mathrm{O} ; 99 \%\right.$ purity), potassium hexacyanoferrate(III) (99.9\% purity), iron(II) chloride $\left(\mathrm{FeCl}_{2} \times 4 \mathrm{H}_{2} \mathrm{O} ; 99 \%\right.$ purity), Trolox $(97 \%$ purity), standard phenolic compounds (>95\% purity), the solvents ethanol (EtOH; 99.5\% purity) and methanol (MeOH; 99.5\% purity), and antiactin antibody were obtained from Sigma-Aldrich Co. (St. Louis, MO, USA). Sodium carbonate $\left(\mathrm{Na}_{2} \mathrm{CO}_{3} ; 99.999 \%\right.$ purity), Folin-Ciocalteu's phenol reagent, tannic acid ( $\mathrm{Ph}$ Eur purity), and aluminium chloride hexahydrate $\left(\mathrm{AlCl}_{3} \times 6 \mathrm{H}_{2} \mathrm{O}\right.$; $\mathrm{Ph}$ Eur purity) were purchased from Merck (Darmstadt, Germany). Furthermore, the reagents for antiviral studies, if not otherwise specified, were purchased from Invitrogen (Carlsbad, CA, USA).

\subsection{Phytochemical Analysis}

2.3.1. Chromatographic Analysis. HPTLC and HPLC-PDA phenolic pattern were evaluated according to previous standardized methods [27]. To perform the HPTLC analysis, the extract and the selected standard polyphenols rutin, chlorogenic acid, catechin, and gallic acid were dissolved in methanol at concentration of $30 \mathrm{mg} / \mathrm{ml}$ and $1 \mathrm{mg} / \mathrm{ml}$, respectively. The phenolics were identified by comparison with the selected standards (Rf values, colors, and UV spectra).

For the HPLC-PDA, the HOP extract $(20 \mu \mathrm{l})$ was dissolved in the mobile phase (1:10 dilution factor) and injected into HPLC-PDA system. The standard phenolics, including benzoic acid, carvacrol, catechin, chlorogenic acid, epicatechin, gallic acid, harpagoside, naringenin, naringin, $\mathrm{p}-\mathrm{OH}$ benzoic acid, quercetin, rutin, sinapinic acid, syringic acid, t-cinnamic acid, t-ferulic acid, and vanillic acid, were enclosed in the analysis.

2.3.2. Total Polyphenols, Tannins, and Flavonoids. The total polyphenol, tannin, and flavonoid content was determined according to standardized spectrophotometric methods, with minor changes [27]. The total amount of both polyphenols and tannins was calculated as tannic acid equivalents (TAE), while flavonoids were expressed as quercetin equivalents (QE).

\subsection{Antiviral Activity}

2.4.1. Cell Cultures. MDCK (Madin-Darby canine kidney) cells and A549 human lung carcinoma cells were grown in RPMI 1640 and DMEM medium, respectively, supplemented 
with $10 \%$ fetal bovine serum (FBS), $0.3 \mathrm{mg} / \mathrm{ml}$ glutamine, $100 \mathrm{U} / \mathrm{ml}$ penicillin, and $100 \mu \mathrm{g} / \mathrm{ml}$ streptomycin.

2.4.2. Cytotoxicity Assay. The cytotoxicity of the treatments was evaluated by using the 3-(4,5-dimethylthiazol-2-yl)-2,5diphenyltetrazolium bromide reduction assay [28]. The HOP extract was dissolved in DMSO (concentrations range $20-180 \mu \mathrm{g} / \mathrm{ml}$ ) and added to both MDCK and A549 cells for $24 \mathrm{~h}$. The cytotoxicity was calculated as percentage reduction in viability of HOP-treated cells compared to control, that is, cells treated with DMSO alone.

In the cytoprotection assay, after a $24 \mathrm{~h}$ pretreatment with the HOP extract, a low-toxic concentration (about $40 \%$ cytotoxicity as found in preliminary experiments) of the prooxidant agent $\mathrm{tBOOH}(5 \mu \mathrm{M})$ was added for $2 \mathrm{~h}$ to cells, and then the cell viability was measured as described above.

2.4.3. Viral Infection, Titration, and Viral $m R N A$ Quantification. Confluent monolayers of MDCK or A549 cells were challenged with the following influenza A virus strains: human A/Puerto Rico/8/34 H1N1 (PR8), A/NWS/ 33 H1N1 (NWS), and pandemic A/California/04/09 H1N1 (pH1N1) strains or avian Parrot/Ulster/73 H7N1 (ULSTER) strain, at a multiplicity of infection (m.o.i.) of 3 (high m.o.i.) and 0.3 (low m.o.i.) for $1 \mathrm{~h}$ at $37^{\circ} \mathrm{C}$. After the viral adsorption, the cells were washed with phosphate-buffered saline (PBS) and then incubated with medium supplemented with $2 \%$ FBS for 24 or $48 \mathrm{~h}$.

For the evaluation of the antiviral activity, HOP extract was dissolved in DMSO and then diluted to the final concentrations in the cell culture medium. The highest DMSO concentration present in the culture medium was $0.2 \%$. Control cells were treated with DMSO alone at the same concentration.

Treatment with HOP was performed as follows: $1 \mathrm{~h}$ before the infection (b.i.), during the $1 \mathrm{~h}$ adsorption period (d.i.), and after the adsorption (postinfection, p.i.) or before, during, and after the infection (b.d.p.i.).

To evaluate the virucidal effect, HOP extract was incubated directly with the virus for $1 \mathrm{~h}$ at $37^{\circ} \mathrm{C}$. Then, the mixture was used to infect the cell culture as described above.

Virus production was determined in the supernatants of infected cells 24 and 48 h p.i., by measuring the hemagglutinating units (HAU) or the tissue culture infectious dose 50 (TCID50), as previously described [29].

For M1 mRNA quantification, total RNA was isolated from A549 cell lysates (Total RNA Purification Plus Kit, Norgen Biotek, Thorold, ON, Canada) and used as a template for generating cDNA (iScript cDNA Synthesis Kit, Bio-Rad, Milan, Italy). An aliquot of the cDNA was subjected to 40 cycles of RT-PCR amplification $\left(95^{\circ} \mathrm{C}, 10 \mathrm{sec} ; 60^{\circ} \mathrm{C}, 30 \mathrm{sec}\right)$ using iQ SYBR Green Supermix and a LightCycler iQ 5 (Bio-Rad, Milan, Italy). The housekeeping gene ribosomal protein L13A (Rpl13a) was used for normalization. Relative quantitative evaluation was performed by the comparative $\Delta \Delta$ Ct method.

2.4.4. Immunoblotting Analysis. Influenza virus-infected and HOP-treated (as described above) MDCK or A549 cells were lysed and analyzed by SDS-PAGE followed by Western blotting with anti-influenza (Merck Millipore, Darmstadt, Germany) and antiactin antibodies. HRP-linked anti-goat and anti-mouse (Jackson ImmunoResearch, Newmarket, UK) were used as secondary antibodies. The membranes were developed using Clarity Western ECL substrate (Bio-Rad, Hercules, CA, USA).

2.4.5. Immunofluorescence Analysis. Following incubation of PR8 virus with HOP extract and infection with the mixture (or with PR8 alone), A549 cells were fixed with methanol, permeabilized with $0.1 \%$ Triton $\mathrm{X}-100$ and stained with anti-NP antibody (Bio-Rad, Hercules, CA, USA). AlexaFlour 488-conjugated anti-mouse was used as secondary antibody. Nuclei were stained with $4^{\prime}, 6$-diamidino-2phenylindole (DAPI).

2.4.6. Glutathione Assay. GSH level was quantified in A549 cell lysates from PR8- or pH1N1-infected and HOP-treated (p.i. and b.d.p.i.) cells, as previously described [30]. The GSH levels were also measured in the lysates from cells treated with the prooxidant agent $\mathrm{tBOOH}(5 \mu \mathrm{M})$. In these experiments, the antioxidant effect of the HOP extract was evaluated under pretreatment and cotreatment plus posttreatment protocols. Protein content was determined with Bradford reagent (Bio-Rad, Hercules, CA, USA) and GSH level expressed as nmol/mg proteins.

2.5. Antioxidant Activity. All tests were performed in 96multiwell microplates away from direct light; the experiments were repeated at least twice, and in each experiment, each concentration was tested in triplicate. Data obtained from at least two experiments were pooled for statistical analysis.

To perform the assays, the HOP extract was dissolved in deionized water, and in each test, the suitable negative or positive controls (Trolox, rutin, and quercetin used as standard antioxidant agents) were included. The absorbance was measured by a microplate reader (Epoch Microplate Spectrophotometer, BioTek).

2.5.1. Radical Scavenging Activity. DPPH and ABTS radical scavenging activities were determined according to Di Sotto et al. [27] with minor changes. Briefly, a DPPH solution $(40 \mu \mathrm{l} ; 0.1 \mathrm{mM}$ in $\mathrm{EtOH} 100 \% v / v)$ and the test sample $(160 \mu \mathrm{l})$ were incubated for 30 minutes in the dark at room temperature, and then the absorbance of DPPH radical was measured at $517 \mathrm{~nm}$. For the ABTS assay, equal volumes of ABTS (5 mM in PBS 0.1 M, pH7.0) and AAPH (2 mM in PBS 0.1 M, pH 7.0) were mixed and incubated for 45 minutes at $68^{\circ} \mathrm{C}$, to obtain the ABTS radical cation. The sample $(20 \mu \mathrm{l})$ was added to the radical solution $(180 \mu \mathrm{l})$, and the plates were incubated for 10 minutes in the dark at $37^{\circ} \mathrm{C}$ and then read at $734 \mathrm{~nm}$. The percentage of scavenger activity was calculated as follows: $100 \times\left(A_{\text {control }}-A_{\text {sample }}\right) / A_{\text {control, }}$ where $A_{\text {control }}$ is the absorbance of the radical alone, while $A_{\text {sample }}$ is that of radical with sample.

2.5.2. Crocin Bleaching Assay. The assay was carried out according to Di Majo et al. [31] with minor changes. To perform the assay, a crocin solution $(40 \mu \mathrm{l} ; 3.5 \mathrm{mM}$ in PBS $0.1 \mathrm{M}$, 
$\mathrm{pH} 7.4)$, AAPH $(10 \mu \mathrm{l} ; 0.25 \mathrm{M}$ in PBS $0.1 \mathrm{M}, \mathrm{pH} 7.4)$, the extract $(40 \mu \mathrm{l})$, and PBS $(110 \mu \mathrm{l} ; 0.1 \mathrm{M}, \mathrm{pH} 7.4)$ were mixed; then the mixture was incubated at $40^{\circ} \mathrm{C}$ in the dark for 60 minutes. After incubation, the crocin absorbance was read at $443 \mathrm{~nm}$. The percentage of antioxidant activity was calculated as follows: $100 \times\left(A_{\text {control }}-A_{\text {sample }}\right) / A_{\text {control, }}$ where $A_{\text {control }}$ is the absorbance of the crocin alone, while $A_{\text {sample }}$ is that of radical with sample.

2.5.3. Inhibition of Lipid Peroxidation. The assay was carried out by the ferric thiocyanate method according to Di Sotto et al. [32]. Briefly, the sample $(125 \mu \mathrm{l})$, PBS $(500 \mu \mathrm{l} ; 0.2 \mathrm{M}$, $\mathrm{pH} 7.0)$, and a linoleic emulsion $(625 \mu \mathrm{l})$ were incubated at $37^{\circ} \mathrm{C}$ for $96 \mathrm{~h}$. Some aliquots $(100 \mu \mathrm{l})$ were taken every $24 \mathrm{~h}$ and further added with ethanol $(470 \mu \mathrm{l} ; 75 \% v / v), \mathrm{FeCl}_{2}$ $(10 \mu \mathrm{l} ; 200 \mathrm{mM}$ in $3.5 \% w / v \mathrm{HCl})$, and potassium hexacyanoferrate (KSCN, $10 \mu \mathrm{l} ; 30 \% w / v$ in deionized water). Peroxides, released during linoleic acid peroxidation, oxidize ferrous to ferric ions, so forming a red ferric(III) thiocyanate complex, measured at $500 \mathrm{~nm}$ spectrophotometrically. The percentage of lipoperoxidation inhibition (LPI) was calculated as follows: $\left[1-\left(A_{\text {sample }} / A_{\text {control }}\right)\right] \times 100$, where $A_{\text {control }}$ was the absorbance of the vehicle while $A_{\text {sample }}$ is that of the tested sample.

2.5.4. Ferric Reducing Activity. The activity was evaluated by the ferrozine assay, according to previous published methods [27]. Briefly, equal volumes of $\mathrm{FeCl}_{3} \times 6 \mathrm{H}_{2} \mathrm{O}(200 \mu \mathrm{M}$ in acetate buffer solution $0.1 \mathrm{M}, \mathrm{pH} 4.5$ ) and the samples were mixed for 2 minutes, and then a ferrozine solution $(5 \mathrm{mM}$ in acetate buffer solution $0.1 \mathrm{M}, \mathrm{pH} 4.5$ ) was added to the mixture. The ferrous ion-ferrozine complex, corresponding to the reducing activity of the sample, was measured at $562 \mathrm{~nm}$ and the percentage of activity was calculated as follows: $100 \times\left(A_{\text {control }}-A_{\text {sample }}\right) / A_{\text {control }}$, where $A_{\text {control }}$ is the absorbance of the vehicle, while $A_{\text {sample }}$ is that of the tested sample.

2.6. Statistical Analysis. For the antioxidant studies, all values are expressed as mean $\pm \mathrm{SE}$ and $n$ represents the number of experiences.

For the antiviral studies, all values are expressed as mean \pm SD and $n$ represents the number of replicates for each treatment.

Statistical analysis was performed by GraphPad Prism $^{\mathrm{TM}}$ software (GraphPad Software Inc., San Diego, California, USA).

The one-way analysis of variance (one-way ANOVA), followed by Dunnett's multiple comparison posttest, was used to analyze the difference among different treatments, while the Student's $t$-test was applied to determine the statistical significance between two different experimental conditions. The values of $P<0.05$ were considered significant.

The concentration-response curves were constructed using the "Hill equation": $E=E \max /\left[1+\left(10_{50}{ }^{\mathrm{LogEC}} / \mathrm{A}\right)^{\text {Hillslope }}\right]$, where $E$ is the effect expressed as increase in the ferrous chelation at a given concentration of agonist, $E \max$ is the maximum ferrous chelating activity, $\mathrm{IC}_{50}$ is the concentration that produces a $50 \%$ of the inhibitory response, $A$ is
TABLE 1: Phenolic composition of the HOP extract by HPLC-PDA analysis.

\begin{tabular}{lc}
\hline Compounds & $\begin{array}{c}\text { Concentration }(\mu \mathrm{g} / \mathrm{mg} \text { of the sample }) \\
(\mathrm{mean} \pm \mathrm{SD})\end{array}$ \\
\hline Benzoic acid & $\mathrm{nd}$ \\
Carvacrol & $\mathrm{nd}$ \\
Catechin & nd \\
Chlorogenic acid & $0.017 \pm 0.001$ \\
t-Cinnamic acid & nd \\
Epicatechin & nd \\
t-Ferulic acid & $0.078 \pm 0.005$ \\
Gallic acid & $0.026 \pm 0.002$ \\
Harpagoside & nd \\
Naringenin & nd \\
Naringin & nd \\
p-OH benzoic acid & $0.029 \pm 0.002$ \\
Quercetin & nd \\
Rutin & $0.363 \pm 0.001$ \\
Sinapinic acid & nd \\
Syringic acid & $0.289 \pm 0.020$ \\
Vanillic acid & BLD \\
\hline
\end{tabular}

BLD: below limit of detection; nd: not detected.

TABLE 2: Amounts of total polyphenols, tannins, and flavonoids in the HOP extract $(n=3)$.

\begin{tabular}{lc}
\hline Compound & $\begin{array}{c}\text { HOP extract }(\mu \mathrm{g} / \mathrm{mg} \text { of the sample) } \\
(\text { mean } \pm \mathrm{SE})\end{array}$ \\
\hline $\begin{array}{l}\text { Total polyphenols (TA } \\
\text { equivalents) }\end{array}$ & $7.1 \pm 0.35$ \\
Tannins (TA equivalents) & $1.7 \pm 0.06$ \\
Flavonoids (Q equivalents) & $3.8 \pm 0.59$ \\
\hline
\end{tabular}

TA: tannic acid; Q: quercetin.

the agonist concentration in molar, and HillSlope is the slope of the agonist curve.

\section{Results and Discussion}

3.1. Phytochemical Analysis. The HPTLC analysis showed the presence in the chromatogram of different polyphenols, evidenced as fluorescent spots, and better visualized by derivatization with NPR and anisaldehyde (Figure S1). Among them, rutin, chlorogenic acid, and gallic acid were identified. The HPLC-PAD analysis confirmed the presence of rutin as one of the most abundant phenolic compounds, along with syringic acid and ferulic acid; lower levels were highlighted for p-OH benzoic acid, gallic acid, and chlorogenic acid (Table 1).

Colorimetric determinations highlighted a polyphenols/ tannins ratio of about 4 , while the flavonoid content agreed with that declared by the supplier (Table 2). On the basis of the DER, the total flavonoid content of the HOP extract resulted to be about $0.4 \%$ of the raw material. According to Peterson and Dwyer [33], which classified the flavonoid concentration in foods as low $(0.1-39.9 \mathrm{mg} / \mathrm{kg})$, 

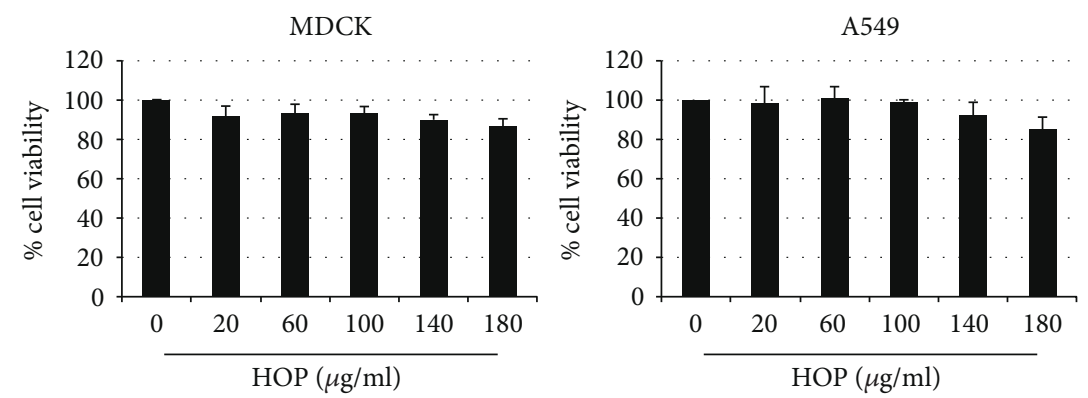

(a)

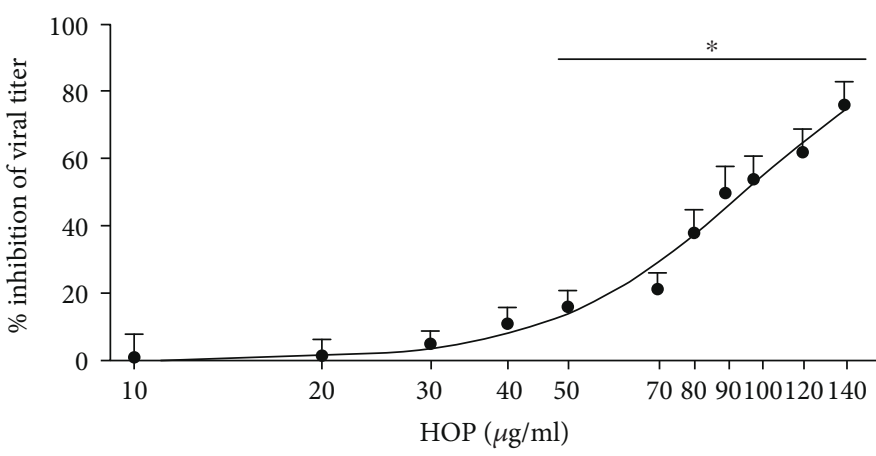

(b)

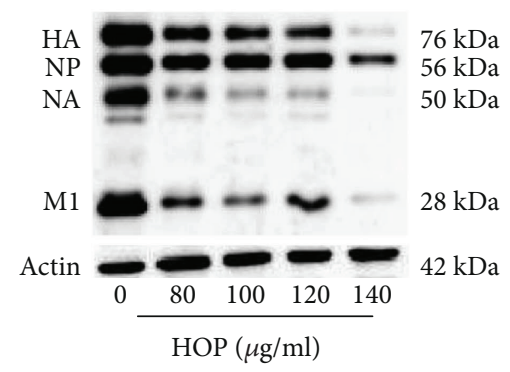

(c)

FIGURE 1: (a) Cell viability (percentage of control) of MDCK and A549 cells treated with different concentrations of HOP extract for $24 \mathrm{~h}$ as evaluated by MTT assay. (b) Percentage of inhibition of viral titer induced by HOP extract (10-140 $\mu \mathrm{g} / \mathrm{ml})$ on MDCK cells infected with PR8 virus (low m.o.i.) and treated with HOP after infection for $24 \mathrm{~h}$. Data are mean \pm SD from three independent biological replicates, each one performed in two technical replicates $(n=3) .{ }^{*} P<0.05$ versus untreated infected cells by Student's $t$-test. (c) Western blot analysis of viral proteins (HA: hemagglutinin; NP: nucleoprotein; NA: neuraminidase; M1: matrix 1 protein) from PR8-infected MDCK cells, treated with HOP $(80-140 \mu \mathrm{g} / \mathrm{ml})$ after infection for $24 \mathrm{~h}$.

moderate (40-99.9 mg/kg), and high (>100 mg/kg), the raw material resulted to contain a high flavonoid (i.e., $950 \mathrm{mg} / \mathrm{kg}$ ) amount, thus suggesting its possible role as a nutraceutical source.

According to our results, Inui et al. [24] highlighted that syringic acid, along with procyanidins and catechins, was the major constituent of a hydroacetone extract from the H. lupulus plant, with lower levels of quercetin, naringenin, kaempferol, and xanthohumol. Ferulic acid was also found in a methanolic extract from cones of $H$. lupulus [34]. Furthermore, quercetin glycosides, such as rutin, isoquercitrin, and isoquercitrin malonate, have been identified as the main bioactive constituents of the water extract from hop plant [35]. Quercetin and kaempferol glycosides were also found in $H$. lupulus cones and young shoots [36, 37].

Our sample of HOP extract did not contain quercetin and naringenin, in spite of a high amount of rutin. This could be a consequence of the mild extraction condition (based on a maceration in ethanol 90\% $v / v$ ), which allows a poor hydrolysis of the glycoside. In fact, the rutin hydrolysis has been found to occur under acidified conditions with high concentrated hydrochloric acid and extended heating times [38]. A significant influence of the extraction method on the phenolic concentration in $H$. lupulus extracts was reported: in spite of a very low phenolic amount in the aqueous extracts, the hydroalcoholic samples were found richer in epicatechin, chlorogenic acid, gallic acid, catechin, benzoic acid, ferulic acid, and o-coumaric acid [39]. The extraction method also affects the total amount of prenylflavonoids and bitter, being poorly stable under prolonged and hot extraction conditions [40].

\subsection{Antiviral Activity}

3.2.1. HOP Extract Inhibits Influenza A Virus Replication in Different Phases of the Virus Life Cycle. In order to study a possible antiviral activity of the HOP extract, first of all it has been necessary to rule out any cytotoxic effect in the tested cell lines. Using concentrations of the extract from 20 to $180 \mu \mathrm{g} / \mathrm{ml}$ on MDCK and A549 epithelial cell lines, we demonstrated that the percentage of cellular viability was equal or higher than $90 \%$ compared to control cells till the concentration of $140 \mu \mathrm{g} / \mathrm{ml}$ in both cell lines (Figure 1(a)). Since a slight reduction (about 13\%) in cell proliferation was observed when cells were treated with HOP $180 \mu \mathrm{g} / \mathrm{ml}$, we chose to exclude this concentration for the following experiments.

Next, we tested the antiviral activity of different concentrations $(10-140 \mu \mathrm{g} / \mathrm{ml})$ of HOP on kidney epithelial MDCK cells, well known to be highly permissive to influenza virus. As shown in Figure 1(b), the extract inhibited PR8 viral replication in a statistically significant $\left({ }^{*} P<0.05\right.$ starting from $50 \mu \mathrm{g} / \mathrm{ml}$ ) and concentration-dependent manner, with an $\mathrm{IC}_{50}$ value of 99 (confidential limits $\left.93-110\right) \mu \mathrm{g} / \mathrm{ml}$. Western 
PR8

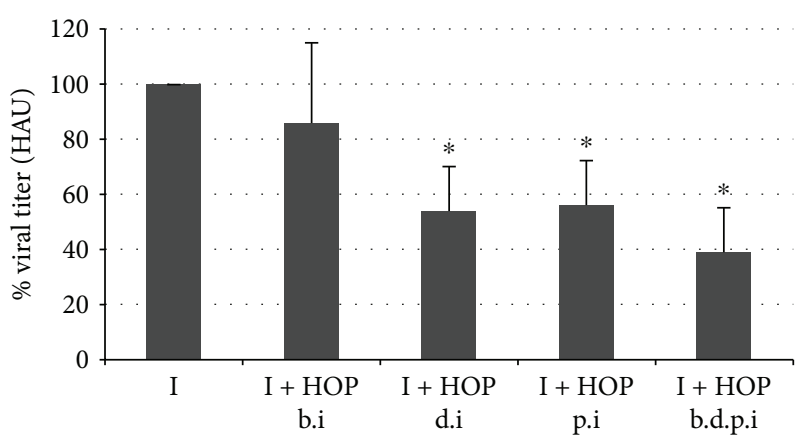

NWS

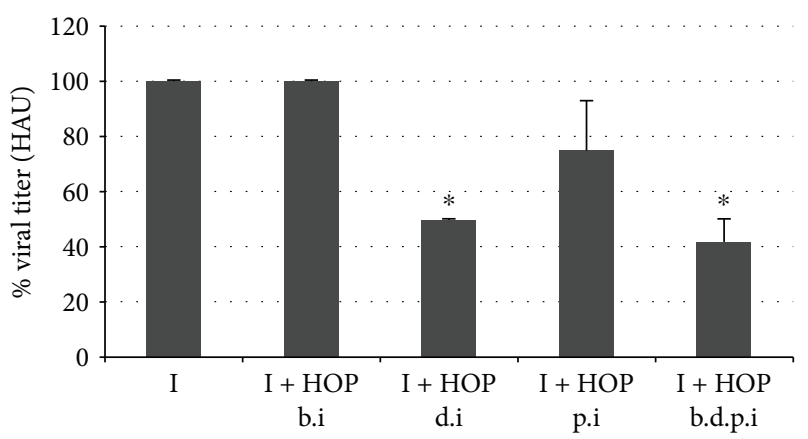

pH1N1

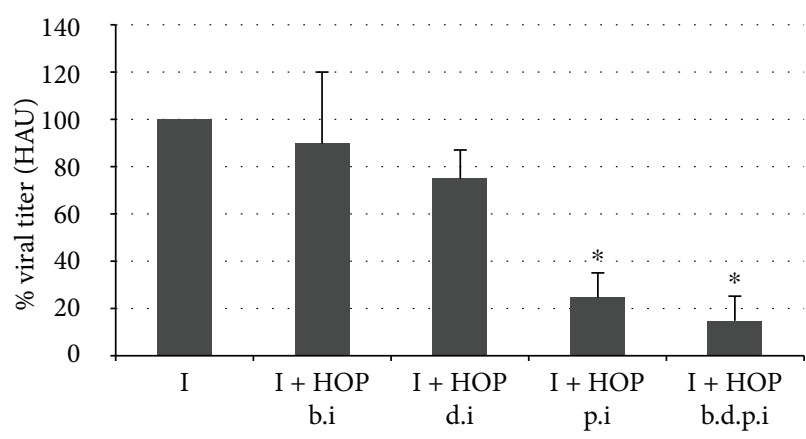

ULSTER

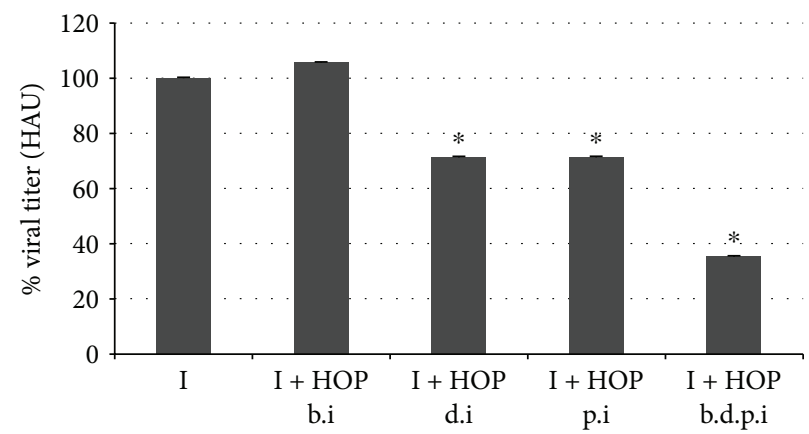

Figure 2: Viral titer measured in supernatants of A549 cells infected with different influenza A virus strains and treated with $140 \mu \mathrm{g} / \mathrm{ml} \mathrm{HOP}$ extract $1 \mathrm{~h}$ before the infection (b.i.), during the $1 \mathrm{~h}$ adsorption period (d.i.), and after the adsorption (postinfection: p.i.) or before, during, and after the infection (b.d.p.i.). Viral production was determined $24 \mathrm{~h}$ p.i. by hemagglutinating assay and expressed as percentage of HAU, (where titer from the untreated, infected cells was considered 100\%). Data are mean \pm SD from three independent biological replicates, each one performed in two technical replicates $(n=3) .{ }^{*} P<0.05$ versus untreated infected cells by Student's $t$-test.

blot analysis of viral proteins similarly showed a dosedependent reduction of hemagglutinin (HA), neuraminidase (NA), nucleoprotein (NP), and matrix protein1 (M1) in infected and HOP-treated cells compared to the infected ones (Figure 1(c)).

On the basis of this preliminary evidence, the highest concentration of $140 \mu \mathrm{g} / \mathrm{ml}$ was chosen for the antiviral assays in the human lung epithelial A549 cells. Particularly, these cells were infected with different strains of influenza A virus (PR8, pH1N1, NWS, and ULSTER) and treated with $\mathrm{HOP}$ at different times from the infection: before (b.i.), during (d.i.), and after (p.i.) or before, during, and after the infection (b.d.p.i). As shown in the charts of Figure 2, the treatment before the infection was ineffective. Instead, when the HOP extract was added to the culture medium with the virus during the $1 \mathrm{~h}$ infection, it was able to reduce viral titer, in a partial but significant degree for PR8, NWS, and ULSTER strains (46\%, 50\%, and 29\% of inhibition, resp.). The HOP treatment performed after the infection significantly reduced pH1N1, PR8, and ULSTER titer (75\%, 44\%, and $29 \%$, resp.). Interestingly, when the treatment was performed before, during, and after the infection, it significantly reduced viral titer of all the strains, suggesting an inhibitory additive effect of the HOP extract, when it was continuously present during all the time of infection.
3.2.2. HOP Extract Exerts a Partial Virucidal Effect. In the attempt of explaining the molecular mechanism exerted by the HOP extract on influenza virus-infected cells, we decided to evaluate different steps of virus life cycle. First, we analyzed the effect of HOP extract during the $1 \mathrm{~h}$ infection. For this step, we could hypothesize a virucidal effect of the extract or an effect on an early phase of the viral life cycle. HOP extract was incubated directly with the virus and then the mixture used to infect the cells, as described in Materials and Methods. PR8 production, measured by the hemagglutinating assay, was significantly inhibited, both when high and low m.o.i. of virus were used, but with a higher percentage of inhibition when low m.o.i. was used (about $70 \%$ and almost $92 \%$ of inhibition, resp., Figure 3(a)). Results were confirmed by using the TCID50 assay, that is, the inhibition in viral replication was $80 \%$ when the extract was incubated with high m.o.i. of virus and over $90 \%$ when low m.o.i. of virus was used, confirming an inhibitory effect of the HOP extract that was viral dose-dependent, as it would be for a virucidal effect (Table 3). Western blot analysis of PR8 proteins obtained from lysates of cells infected with PR8-HOP mixture showed a lower expression of viral proteins compared to those in cells infected with the virus alone (Figure 3(b)). Similar results were obtained when cells were infected with other viral strains preincubated with HOP extract (see Figure S2). Furthermore, in 


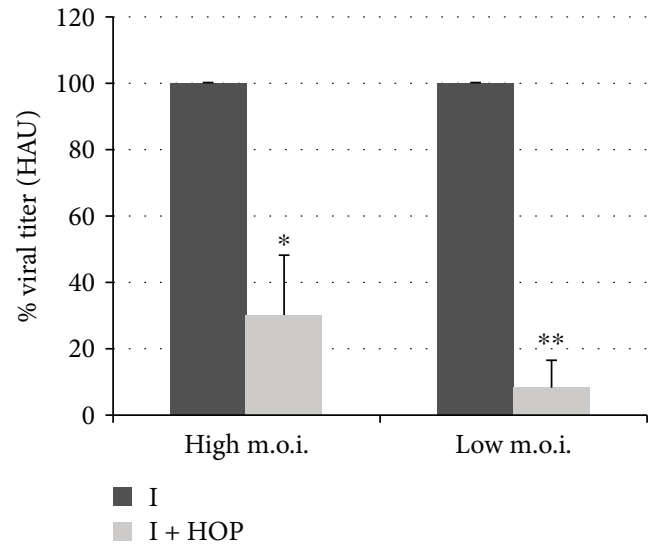

(a)

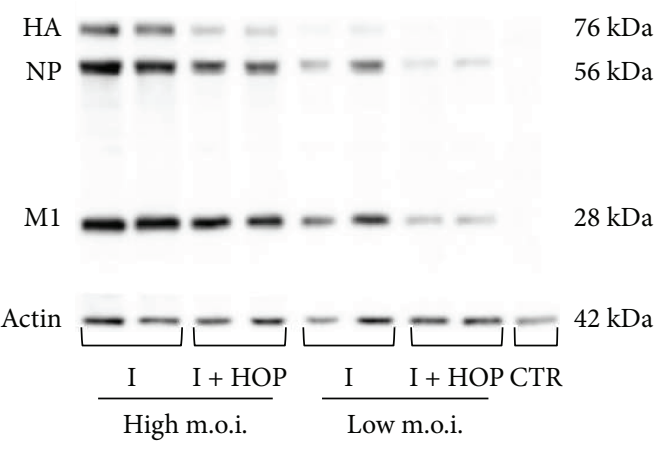

(b)

FIGURE 3: (a) Viral titer measured in supernatants of A549 cells infected with PR8 virus (high or low m.o.i.), following incubation of the virus with $140 \mu \mathrm{g} / \mathrm{ml} \mathrm{HOP}$ extract. Titer was determined $24 \mathrm{~h}$ p.i. by hemagglutinating assay and expressed as percentage of HAU compared to that from cells infected with untreated virus. Data are mean \pm SD from three independent biological replicates, each one performed in two technical replicates $(n=3) .{ }^{*} P<0.05$ and ${ }^{* *} P<0.01$ versus untreated infected cells by Student's $t$-test. (b) Western blot analysis of viral proteins from samples obtained as described in (a). Actin was used as loading control.

TABLE 3: TCID $_{50}$ from supernatants of A549 cells infected with PR8 virus following incubation of the virus with $140 \mu \mathrm{g} / \mathrm{ml} \mathrm{HOP.}$

\begin{tabular}{lcc}
\hline Viral titer TCID50/ml & I high m.o.i. & I + HOP high m.o.i. \\
$24 \mathrm{~h}$ & 1585 & 316 \\
$48 \mathrm{~h}$ & 3162 & 631 \\
\hline & I low m.o.i. & I + HOP low m.o.i. \\
$24 \mathrm{~h}$ & $\mathrm{ND}$ & $\mathrm{ND}$ \\
$48 \mathrm{~h}$ & 35481 & 3162 \\
\hline
\end{tabular}

these conditions, an immunofluorescence analysis of the viral nucleoprotein (NP) was performed using low m.o.i. of virus. According with Western blot results, the images in Figure 4 showed that NP was less expressed in cells infected with the virus-HOP mixture compared to the infected ones. Collectively, these results indicate that the HOP extract exerts at least a partial direct effect on viral particles, reducing their infectious ability. It has been already shown that the extract exerts an injurious effect on bacterial cell structures; in particular, its hydrophobic components are incorporated into the cell membranes, altering ion exchange [23]. Therefore, it is plausible that HOP components could be incorporated in the membrane of enveloped viruses, as influenza, destabilizing viral structure. However, we cannot exclude that HOP could enter the cells and act in an early phase of the cycle. Looking at the immunofluorescence images, the localization of NP appeared also affected, being in the nuclei of the HOP-treated infected cells, while it was diffused throughout the cell (nuclei plus cytoplasm) in untreated infected cells (Figure 4). This result suggests that the HOP components could also enter the cell and act by interfering with virus-activated cellular pathways, that in turn control NP traffic and localization.

To deep inside the mechanisms hypothesized, we performed a second set of experiments during the first replication cycle of the virus. First of all, we repeated an immunofluorescence analysis of viral NP using high m.o.i. of virus for $4 \mathrm{~h}$ and $8 \mathrm{~h}$ of infection. As shown in Figure 5(a), left panel, NP was localized both in the nuclei and the cytoplasm of infected cells with an increased intensity from $4 \mathrm{~h}$ p.i. to $8 \mathrm{~h}$ p.i., accordingly with the progression of the viral life cycle. When the virus was preincubated with HOP (middle panel), the pictures appeared different, as a weak, diffused staining was visible with some brighter spot at $4 \mathrm{~h}$ p.i., which could represent viral particles sticking to the cell membranes and a lower number of infected cells at $8 \mathrm{~h}$ p.i. Moreover, in the cells that were infected, NP was localized mainly in the nuclei. When the cells were infected and treated with HOP after infection (right panel), the main effect was a different NP localization, being the viral protein mainly in the nuclei of infected cells at $8 \mathrm{~h}$ p.i.

qRT-PCR of mRNA levels of viral M1 performed at $2 \mathrm{~h}$ p.i. (Figure 5(b)) revealed a decrease in the expression of M1 mRNA in cells infected and HOP treated with different procedures, but especially with virus-HOP mixture, that could be the result of the reduced number of cells being infected. Accordingly, TCID50 from supernatants of infected cells $8 \mathrm{~h}$ p.i. showed higher inhibition when cells have been infected with virus-HOP mixture (Figure 5(c)).

3.2.3. HOP Extract Restores the Intracellular GSH Levels of Influenza Virus-Infected Cells. In the present study, we also observed that HOP extract exerts an antiviral effect when added after the infection and especially before, during, and after the infection. These data let us to hypothesize that HOP could act also in another step of virus life cycle, with a further mechanism, that is, interfering with the redox imbalance caused by influenza virus. It is well known in fact that on the one hand, other $H$. lupulus extracts and some polyphenols exhibited antioxidant properties [23]; on the other hand, several viruses, including influenza, induce an oxidative stress to activate redox-sensitive pathways useful 

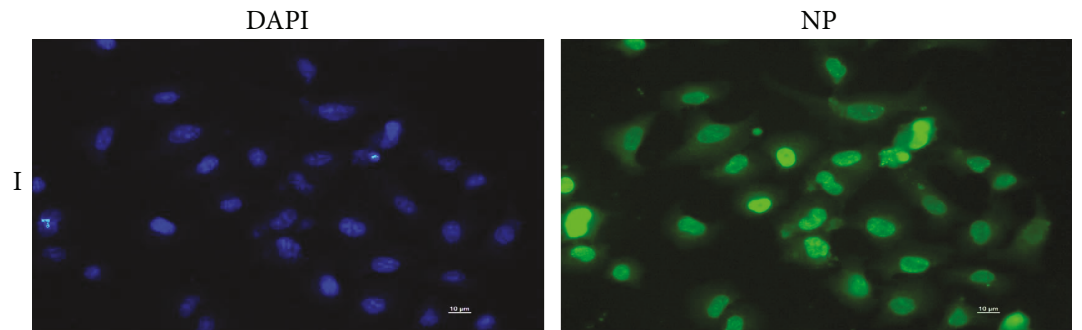

(a)
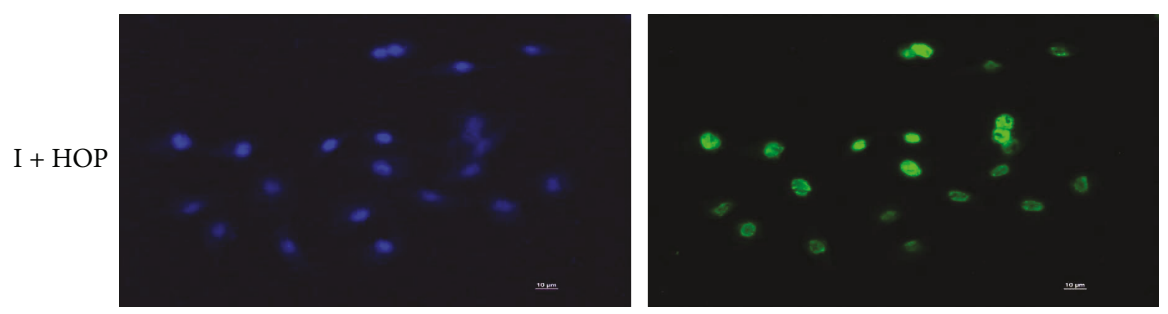

(b)

FIGURE 4: Immunofluorescence images of viral nucleoprotein (green fluorescence) in A549 cells infected for $24 \mathrm{~h}$ with PR8 virus (a) and following incubation of the virus with $140 \mu \mathrm{g} / \mathrm{ml} \mathrm{HOP} \mathrm{(b).} \mathrm{Nuclei} \mathrm{were} \mathrm{stained} \mathrm{with} \mathrm{DAPI} \mathrm{(blue).}$

for their replication $[8,41]$ and a marker of redox changes is represented by glutathione (GSH) depletion in infected cells $[29,42]$. Therefore, we measured the GSH levels in infected cells and HOP-treated after or before, during, and after the infection. Results were compared to infected and uninfected cells (control, CTR). As we expected, viral infection caused a significant GSH depletion (Figure 6). Interestingly, treatment with the HOP extract after the infection was able to restore GSH levels of about $30 \%$ and $40 \%$ (in PR8- and pH1N1-infected cells, compared to control). A more significant antioxidant effect was found when HOP extract was added before, during, and after the infection, and indeed, the GSH content reached $60 \%$ (in pH1N1infected cells) and 73\% (in PR8-infected ones) of that measured in control cells.

In the attempt to explain if the higher GSH content upon HOP treatment could be due to a reduced virus infection or a regulatory effect of the extract, the A549 cells were treated for $2 \mathrm{~h}$ with the prooxidant agent $\mathrm{tBOOH}$ after a $24 \mathrm{~h}$ pretreatment with the HOP extract. In these experimental conditions, $\mathrm{tBOOH}$ induced a slight but significant reduction of cell viability (about 20\% lower than the vehicle) which disappeared in the presence of HOP (Figure S3a). These data were also confirmed in Caco-2 cells (Figure S3b), which represent a widely standardized model for studying oxidative stressinduced toxicity and the effect of dietary antioxidants [43]. Also, the GSH levels were markedly reduced by $\mathrm{tBOOH}$ (at least $70 \%$ reduction respect to the vehicle in all the experimental conditions), as confirmed by the cell morphology changes (Figures S4 and S5). Adding the HOP extract to cells, both under pretreatment and cotreatment plus posttreatment protocols, was able to partly counteract the $\mathrm{tBOOH}$-induced oxidative toxicity and the cell morphology change (Figures S4 and S5). This evidence confirms our hypothesis about the antioxidant power of the tested sample, although the higher GSH levels found in the PR8-infected cells with respect to those damaged by
$\mathrm{tBOOH}$ suggest that combined virucidal and antioxidant mechanisms can contribute to the antiviral properties of the HOP extract. Overall, the results indicate that HOP extract actually acts as antioxidant into infected cells. It could buffer reactive oxygen species (ROS), which are produced during infection [44], and in this way, it could reduce GSH depletion. This event in turn could block some redoxregulated cell pathways important for influenza virus replication. A lot of polyphenols have been shown able to inhibit for example phosphorylation of MAP kinases, including p38 MAPK and ERK, that are involved in the NP traffic $[4,9,45]$. Further studies are needed to distinguish the molecular pathways involved in the HOP extract antiviral effect.

3.3. Antioxidant Activity. During influenza virus infection, the NADPH oxidase isoform 4 (NOX4) is the main source of ROS production [8]. Indeed, inhibition of NOX4 activity or RNA silencing for this enzyme, by blocking ROS increase, prevents MAPK phosphorylation and inhibits NP traffic and viral release. In order to clarify the possible mechanisms by which the HOP extract exerted antioxidant effects in the influenza virus-infected cells, different in vitro antioxidant assays were performed. The radical scavenging properties of the sample, based on hydrogen and electron transfer, were evaluated against the synthetic chromogenic DPPH and ABTS radicals. Particularly, the HOP extract $(0.001-2 \mathrm{mg} / \mathrm{ml})$ inhibited, in a significant and concentration-dependent manner, both DPPH and ABTS radicals, as confirmed by the $\mathrm{IC}_{50}$ values (Table 4 ). The positive control Trolox was about 115- and 150-fold more effective against DPPH and ABTS, respectively. According to the Pearson analysis, these activities were significantly correlated (Table 5), although the sample was most potent (almost twofold) against ABTS, likely suggesting a major involvement of the electronic transfer in the scavenger activity. Taking into account that DPPH and ABTS radicals strongly differ for 

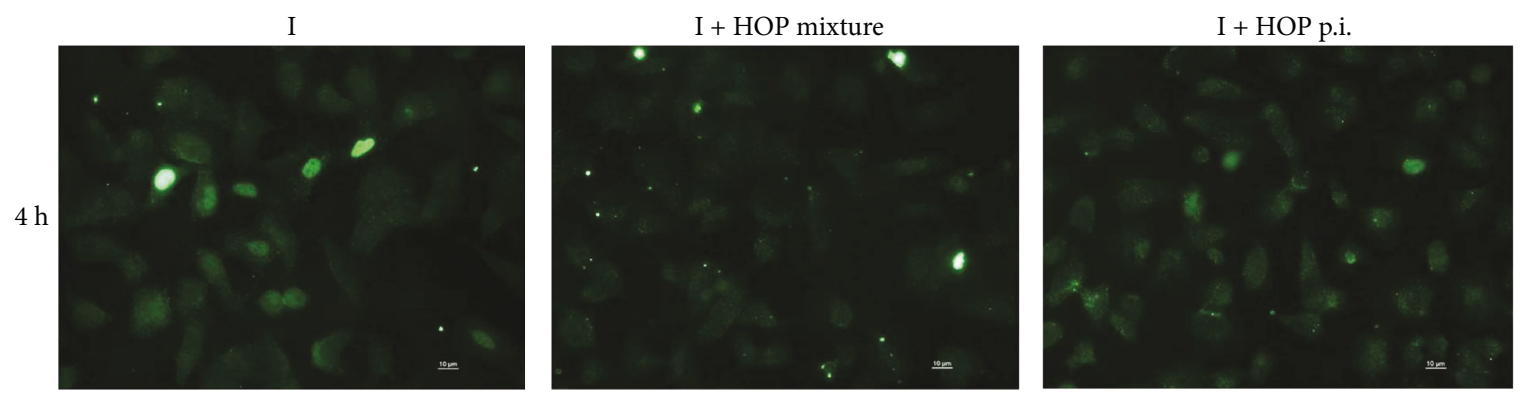

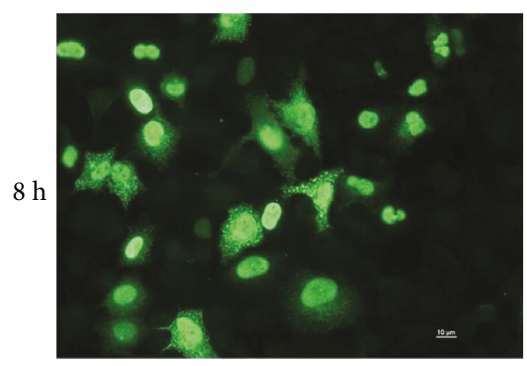

2

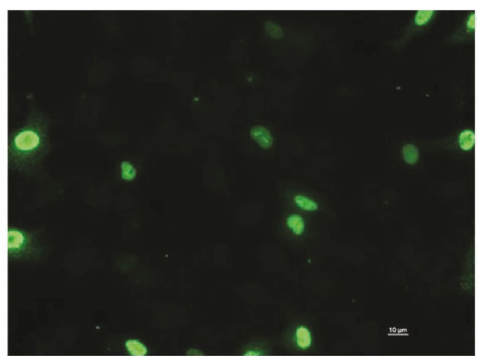

0

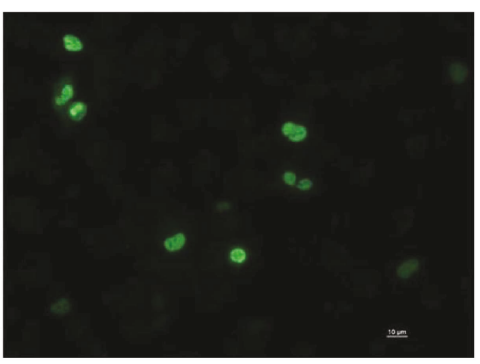

0

$(\mathrm{HAU} / \mathrm{ml})$

(a)

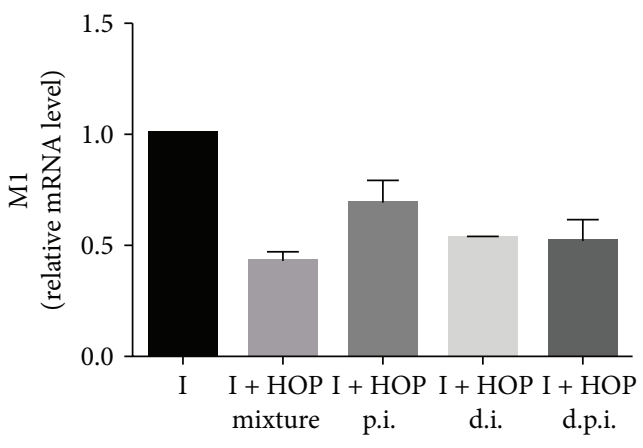

\begin{tabular}{lccc}
\hline $\begin{array}{l}\text { Viral titer } \\
(\text { TCID50/ml) }\end{array}$ & I & $\begin{array}{l}\text { I+HOP } \\
\text { mixture }\end{array}$ & $\begin{array}{c}\text { I+HOP } \\
\text { p.i. }\end{array}$ \\
\hline $24 \mathrm{~h}$ & $10^{1.8}$ & $10^{1.47}$ & $10^{1.6}$ \\
$48 \mathrm{~h}$ & $10^{2.5}$ & $10^{1.79}$ & $10^{2.1}$ \\
\hline
\end{tabular}

(b)

(c)

FIGURE 5: (a) Immunofluorescence images of viral nucleoprotein (green fluorescence) in A549 cells infected for $4 \mathrm{~h}$ and $8 \mathrm{~h}$ with PR8 virus (left panel), with PR8 and $140 \mu \mathrm{g} / \mathrm{ml}$ HOP mixture (middle panel) or HOP treated after PR8 infection (right panel). HAU/ml values ( $8 \mathrm{~h}$ p.i.) are reported below the images. (b) M1 mRNA levels measured by qRT-PCR in A549 cells infected with PR8 virus for $2 \mathrm{~h}$, with PR8/ HOP mixture or HOP treated during (d.i.), after (p.i.), or during plus after (d.p.i.) infection. (c) TCID $_{50}$ from supernatants harvested $8 \mathrm{~h}$ p.i. of same samples as in (a).

PR8

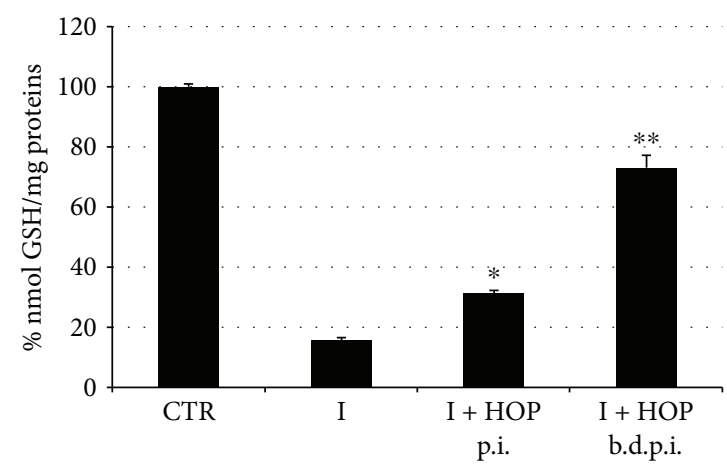

$\mathrm{pH} 1 \mathrm{~N} 1$

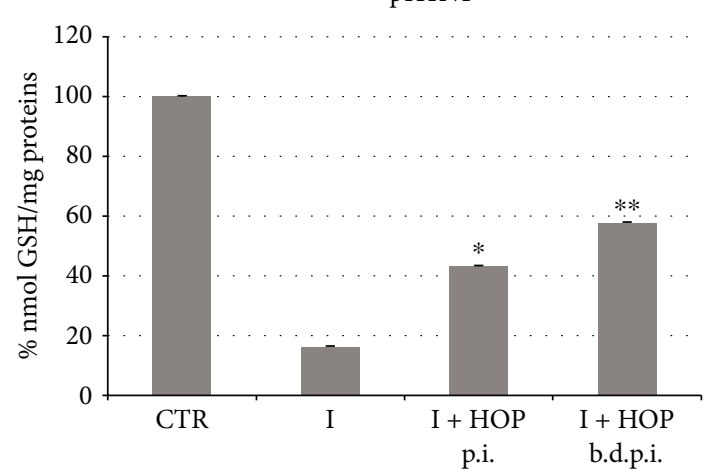

FIGURE 6: GSH levels measured in A549 cell lysates infected with PR8 or pH1N1 virus and treated with $140 \mu \mathrm{g} / \mathrm{ml} \mathrm{HOP}$ extract after the adsorption (postinfection: p.i.) or before, during, and after the infection (b.d.p.i.). Levels are expressed as percentage of nmol/mg proteins (where levels from control cells were considered 100\%). Data are mean \pm SD from three independent biological replicates $(n=3)$. ${ }^{*} P<0.05$ and ${ }^{* *} P<0.01$ versus infected cells by Student's $t$-test. 
TABLE 4: $\mathrm{IC}_{50}$ values of the HOP extract and the standard antioxidant agent Trolox in the antioxidant assays.

\begin{tabular}{lcr}
\hline & HOP extract & Trolox \\
\hline DPPH scavenging activity & $\mathrm{IC}_{50}(\mathrm{CL}) \mu \mathrm{g} / \mathrm{ml}$ & $5.0(4.4-5.8)$ \\
ABTS scavenging activity & $574.1(392.1-840.3)$ & $2.1(1.6-2.4)$ \\
Inhibition of crocin bleaching & $311.1(724.5-1146.2)$ & $6.6(3.7-11.5)$ \\
Lipoperoxidation inhibition & $288.6(270.8-320.4)$ & $3.0(1.1-7.6)$ \\
$\mathrm{Fe}^{3+}$ reducing activity & $124.1(91.2-168.7)$ & $1.5(1.1-2.0)$ \\
\hline
\end{tabular}

TABle 5: Pearson correlation coefficient among antioxidant activity assays for the HOP extract.

\begin{tabular}{|c|c|c|c|c|c|}
\hline & $\begin{array}{l}\text { DPPH scavenger } \\
\text { activity }\end{array}$ & $\begin{array}{c}\text { ABTS scavenger } \\
\text { activity }\end{array}$ & $\begin{array}{c}\text { Pearson's } r\left(\mathrm{CL} ; R^{2}\right) \\
\text { Crocin bleaching } \\
\text { inhibition }\end{array}$ & $\begin{array}{l}\text { Lipoperoxidation } \\
\text { inhibition }\end{array}$ & $\begin{array}{c}\mathrm{Fe}^{3+} \text { reducing } \\
\text { activity }\end{array}$ \\
\hline $\begin{array}{l}\text { DPPH scavenger } \\
\text { activity }\end{array}$ & 1 & - & - & - & - \\
\hline $\begin{array}{l}\text { ABTS scavenger } \\
\text { activity }\end{array}$ & $\begin{array}{c}0.97^{* *}(0.83-0.99 \\
0.95)\end{array}$ & 1 & - & - & - \\
\hline $\begin{array}{l}\text { Crocin bleaching } \\
\text { inhibition }\end{array}$ & $\begin{array}{c}0.96^{* *}(0.53-0.99 \\
0.93)\end{array}$ & $\begin{array}{c}0.99^{* *}(0.86-0.99 \\
0.98)\end{array}$ & 1 & - & - \\
\hline $\begin{array}{l}\text { Lipoperoxidation } \\
\text { inhibition }\end{array}$ & $\begin{array}{c}0.96^{*}(0.23-0.99 \\
0.92)\end{array}$ & $\begin{array}{c}0.99^{* *}(0.81-0.99 \\
0.99)\end{array}$ & $0.99^{* *}(0.3-0.99 ; 0.99)$ & 1 & - \\
\hline $\mathrm{Fe}^{3+}$ reducing activity & $\mathrm{nsc}$ & $\mathrm{nsc}$ & nsc & $0.88^{*}(0.3-0.92 ; 0.78)$ & 1 \\
\hline
\end{tabular}

${ }^{*} P<0.05$ or ${ }^{* *} P<0.01$, statistically significant correlation (two-tailed $t$-test). nsc: not significantly correlated; CL: confidential limits.

chemical structures, affinities, and kinetics of reaction, a higher affinity of the HOP constituents for ABTS can be hypothesized. A hydroalcoholic extract from $H$. lupulus cones exhibited radical scavenging effects of DPPH radical at higher concentrations with respect to hexane and methanol extract, although it contained high levels of gallic acid, quercetin, and kaempferol derivatives: this suggests that these compounds could not be the main responsible for the radical scavenging properties of the extract [34]. A weakly $\mathrm{DPPH}$ scavenging activity was also reported for the leaves of Humulus lupulus [46].

Under our experimental condition, the HOP extract also exhibited antioxidant effect in the crocin bleaching assay (Figure 7 ), being the $\mathrm{IC}_{50}$ value about 44 -fold higher than that of Trolox (Table 4). Crocin bleaching represents a common antioxidant method, which uses crocin as the substrate and AAPH as a source of free radicals: the antioxidant competes with crocin and interferes with the bleaching of crocin. This assay is classified among those that involve the transfer of one hydrogen and is suitable for aqueous systems [47]. On the basis of the Pearson analysis, the crocin bleaching inhibition by extract resulted significantly correlated with the scavenger activity of both DPPH and ABTS radicals (Table 5). Although both DPPH and crocin bleaching assays are based on the hydrogen transfer for blocking radicals, the HOP extract resulted most potent against the crocin-derived radicals respect to DPPH radical. This difference could be due to the reaction media required for each assay (an aqueous medium for crocin solubilization, while methanol or ethanol for DPPH) [48], in which certain bioactive compounds can be low soluble and thus weakly effective. In this context, the aqueous medium seems to favor the radical scavenging properties of the HOP extracts, thus suggesting the presence of hydrosoluble bioactive constituents.

The HOP extract was also found able to inhibit the lipid peroxidation in the ferric thiocyanate assay, already at low concentrations (Figure 8 ), as confirmed by the $\mathrm{IC}_{50}$ value (Table 4). Lipid peroxidation consists of a series of free radical-mediated chain reaction processes and is associated with several types of biological damage [48]. The ferric thiocyanate method, here used, measures the amount of peroxides, which are produced by lipid oxidation during the initial stages of ROS damage. In this assay, hydroperoxides are produced from the autoxidization of linoleic acid and are measured indirectly by the formation of ferric thiocyanate complex. According to the Pearson analysis, the inhibition of lipoperoxidation by HOP extract resulted significantly correlated with its radical scavenger activity (Table 5), thus suggesting that blocking the radical species can prevent the induction of lipid peroxidation. Taking into account that lipid peroxidation represents a major form of cellular oxidation damage, initiated by hydroxyl free radical through the extraction of hydrogen atom from unsaturated fatty acids of membrane phospholipids [49], we can hypothesize that HOP extract can interfere with the peroxidation of the cell biomembranes (by direct ROS neutralization or by blocking their generation) and prevent their structural changes, thus resulting in cytoprotective effects.

Under our experimental conditions, the extract resulted also able to reduce the ferric ions, although with a lower potency (about 140-fold) than the positive control Trolox 


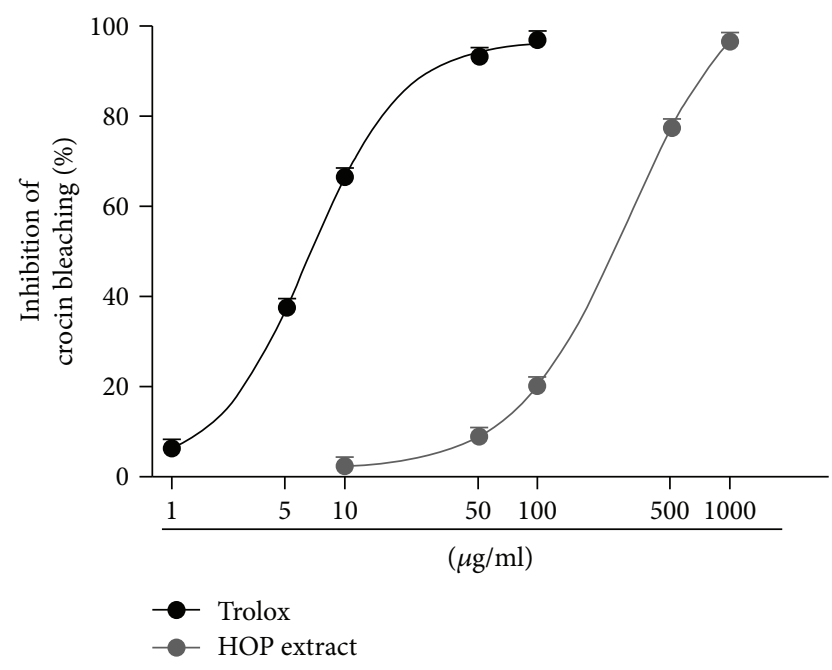

FIgURE 7: Effect of HOP extract on the AAPH-induced crocin bleaching after $24 \mathrm{~h}$ of incubation. Data are mean \pm SE from two independent experiments, each one performed in two technical replicates $(n=4)$.

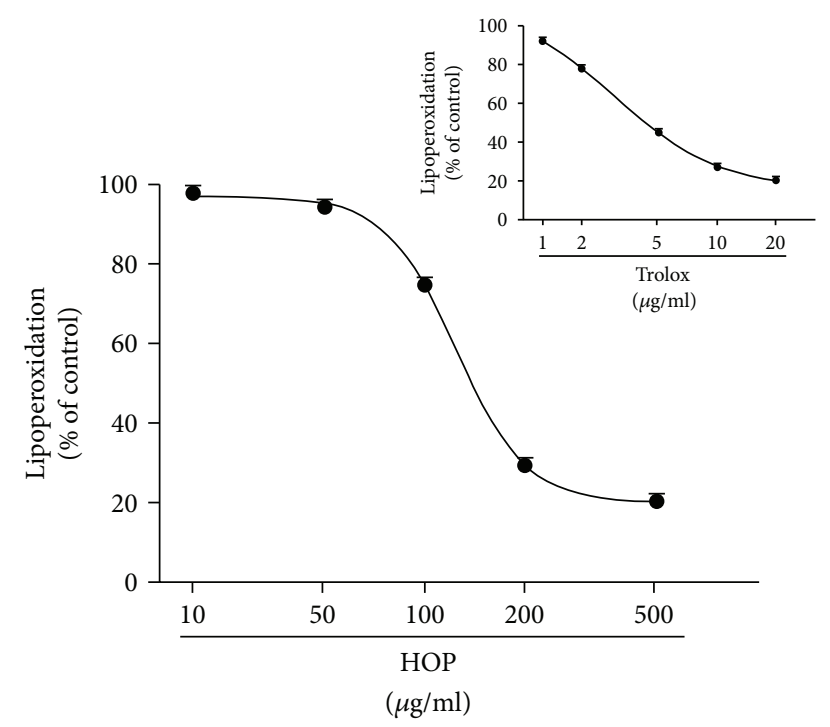

Figure 8: Effect of HOP extract on the linoleic acid oxidation (24 h of incubation) as measured by the ferric thiocyanate method. Data are mean \pm SE from two independent experiments, each one performed in two technical replicates $(n=4)$.

(Table 4). As estimated by the Pearson analysis, the $\mathrm{Fe}^{3+}$ reducing activity appeared to be related with the lipoperoxidation inhibition (Table 5). ROS species production can be also facilitated by elemental species, such as iron, involved in metal-catalysed oxidation of biological substrates and in oxygen reactive species generation [48]. Ferric reducing power, based on the electron donating capacity of the antioxidant, represents a further antioxidant and cytoprotective mechanism, since reducing species can be oxidized in place of biological substrates [50]. In this context, our results showed that the HOP extract contains reducing species, which can be involved in the inhibition of
TABle 6: Pearson correlation coefficient between antiviral activity and antioxidant activity of the HOP extract.

\begin{tabular}{lc}
\hline Antiviral activity & Pearson's $r\left(\mathrm{CL} ; R^{2}\right)$ \\
\hline DPPH scavenger activity & $\mathrm{nsc}$ \\
ABTS scavenger activity & $\mathrm{nsc}$ \\
Crocin bleaching inhibition & $0.99^{* *}(0.53-0.99 ; 0.98)$ \\
Inhibition of lipoperodixation & $0.99^{* *}(0.63-0.99 ; 0.98)$ \\
$\mathrm{Fe}^{2+}$ chelating activity & $0.99^{* *}(0.88-0.99 ; 0.99)$ \\
\hline${ }^{* *} P<0.01$, statistically significant correlation (two-tailed $t$-test). nsc: not \\
significantly correlated; CL: confidential limits.
\end{tabular}

lipid peroxidation. This effect should also contribute to counteract the redox imbalance induced by viral infections, thus mediating both cytoprotective and antiviral effects. Accordingly, the Pearson analysis indicated that the antiviral activity of HOP extract was significantly correlated with its antioxidant properties, particularly $\mathrm{Fe}^{3+}$ reducing activity and lipoperoxidation inhibition (Table 6).

Taken together, present results suggest that the HOP extract is able to interfere both directly and indirectly with the ROS-mediated cell injury. It is also plausible that HOP extract might interfere with NOX4 enzyme or with downstream pathways that are activated by oxidative stress.

Antioxidant properties of $H$. lupulus have been widely ascribed to its phenolic constituents. The most significant antioxidant activities are displayed by prenylated chalcones (i.e., xanthohumol) mainly due to their prenyl group [51]. Prenylflavonoids were reported able to chelate bivalent metals, thereby inhibiting the ROS generation. On the other hand, the antioxidant properties of different polyphenols, such as quercetin, chlorogenic acid, syringic acid, benzoic acid, catechin, and epigallocatechin, have been published $[24,52]$. Therefore, all these compounds can contribute to the biological activity of the extract.

\section{Conclusion}

In the present study, we described the antiviral properties of a hydroalcoholic extract from the female inflorescences of $H$. lupulus, focusing on its ability to both directly counteract the viral replication and viral protein synthesis and indirectly increase the hosting cell defense by antioxidant mechanisms, likely due to its phenolic content.

Very limited evidence on the antiviral properties of $H$. lupulus and its characteristic constituents is available in literature. Buckwold et al. [25] found no antiviral effects of hop crude extracts and its chalcones against the influenza $\mathrm{A}$ and B viral strains.

$H$. lupulus cones represent an important source of phenolic compounds, some of which are reported to produce inhibitory effects against several viral infections [53-58]. Particularly, among the polyphenols identified in the HOP extract, rutin and quercetin were reported to inhibit the influenza infection in animal models, as well as the viral neuraminidase activities in vitro [59-61] and syringic acid and gallic acid were found to be potent anti- 
influenza compounds [62, 63]. This evidence supports our hypothesis about the possible involvement of the phenolic constituents in the antiviral properties of the HOP extract. Particularly, rutin, syringic acid, and gallic acid appear to be the potential bioactive constituents, although the contribution of all the phytocomplex cannot be excluded. Altogether, these compounds can act by both interfering with the virion life cycle and by reinforcing the defenses of hosting cells, mainly counteracting the redox imbalance required for the viral infection establishment.

In conclusion, our results suggest that the HOP extract is able to exert dual antiviral and cytoprotective effects, which can be useful in the prevention and treatment of influenza. Further investigations are encouraged in order to define the possible application of the HOP extract as an antiinfluenza remedy or in combination with conventional antiviral drugs.

\section{Data Availability}

The high-performance thin-layer chromatography (HPTLC) of the HOP extract and its effect on replication of different influenza viral strains, on the oxidative damage and GSH level induced by tert-butyl hydroperoxide in A549 cells are available in the Supporting Materials.

\section{Conflicts of Interest}

The authors have nothing to declare.

\section{Authors' Contributions}

Antonella Di Sotto and Paola Checconi equally contributed to this work.

\section{Acknowledgments}

This work was partially supported by the Ateneo (Lucia Nencioni, Antonella Di Sotto, and Anna Teresa Palamara) and MIUR-PRIN2015W729WH (Anna Teresa Palamara) grants. Antonella Di Sotto, Silvia Di Giacomo, and Stefania Carissimi fellowships were supported by the "Enrico and Enrica Sovena" Foundation (Italy), while Paola Checconi fellowship was supported by the Istituto Pasteur ItaliaFondazione Cenci Bolognetti.

\section{Supplementary Materials}

Figure S1: high-performance thin-layer chromatography (HPTLC) of the polyphenolic compounds of the HOP extract. (a) Visualization at $366 \mathrm{~nm}$ without derivatization. (b) Visualization at $366 \mathrm{~nm}$ after natural product reagent (NPR) derivatization. (c) Visualization under white light after NPR and anisaldehyde derivatization. (d) Visualization at $366 \mathrm{~nm}$ after anisaldehyde/NPR derivatization. (e) Visualization at $255 \mathrm{~nm}$. Figure S2: effect of the HOP extract on replication of different influenza viral strains in A549 cells. (a) Viral titer measured in supernatants of A549 cells infected with pH1N1, NWS, or ULSTER strain, following incubation of the virus with $140 \mu \mathrm{g} / \mathrm{ml}$ of HOP extract. (b) Western blot analysis of viral proteins from samples obtained as described in (a). Figure S3: effect of the HOP extract $(60-140 \mu \mathrm{g} / \mathrm{ml})$ on the oxidative damage induced by tert-butyl hydroperoxide (tBOOH; $5 \mu \mathrm{M}$ ) in A549 (a) and Caco-2 cells (b). Figure S4: GSH levels measured in A549 cell lysates treated with $\mathrm{tBOOH}$ or $\mathrm{tBOOH}$ and $\mathrm{HOP}$ extract $(140 \mu \mathrm{g} / \mathrm{ml})$ under pretreatment (a) and cotreatment plus posttreatment (b) protocols. Figure S5: morphology of A549 cells treated with $\mathrm{tBOOH}$ or $\mathrm{tBOOH}$ and HOP extract $(140 \mu \mathrm{g} / \mathrm{ml})$ under the cotreatment plus posttreatment protocol. (Supplementary Materials)

\section{References}

[1] R. E. Malosh, E. T. Martin, J. R. Ortiz, and A. S. Monto, "The risk of lower respiratory tract infection following influenza virus infection: a systematic and narrative review," Vaccine, vol. 36, no. 1, pp. 141-147, 2018.

[2] https://www.fda.gov/Drugs/drugsafety/informationbydrugclass/ ucm 100228.htm\#ApprovedDrugs.

[3] T. Watanabe and Y. Kawaoka, "Influenza virus-host interactomes as a basis for antiviral drug development," Current Opinion in Virology, vol. 14, pp. 71-78, 2015.

[4] A. T. Palamara, L. Nencioni, K. Aquilano et al., "Inhibition of influenza A virus replication by resveratrol," The Journal of Infectious Diseases, vol. 191, no. 10, pp. 1719-1729, 2005.

[5] P. Matarrese, L. Nencioni, P. Checconi et al., "Pepstatin A alters host cell autophagic machinery and leads to a decrease in influenza A virus production," Journal of Cellular Physiology, vol. 226, no. 12, pp. 3368-3377, 2011.

[6] R. Saladino, V. Neri, P. Checconi et al., "Synthesis of 2 '-deoxy$1^{\prime}$-homo- $N$-nucleosides with anti-influenza activity by catalytic methyltrioxorhenium (MTO) $/ \mathrm{H}_{2} \mathrm{O}_{2}$ oxyfunctionalization," Chemistry, vol. 19, no. 7, pp. 2392-2404, 2013.

[7] R. Sgarbanti, L. Nencioni, D. Amatore et al., "Redox regulation of the influenza hemagglutinin maturation process: a new cellmediated strategy for anti-influenza therapy," Antioxidants \& Redox Signaling, vol. 15, no. 3, pp. 593-606, 2011.

[8] D. Amatore, R. Sgarbanti, K. Aquilano et al., "Influenza virus replication in lung epithelial cells depends on redox-sensitive pathways activated by NOX4-derived ROS," Cellular Microbiology, vol. 17, no. 1, pp. 131-145, 2015.

[9] R. Fioravanti, I. Celestino, R. Costi et al., "Effects of polyphenol compounds on influenza A virus replication and definition of their mechanism of action," Bioorganic \& Medicinal Chemistry, vol. 20, no. 16, pp. 5046-5052, 2012.

[10] T. Bozzini, G. Botta, M. Delfino et al., "Tyrosinase and layerby-layer supported tyrosinases in the synthesis of lipophilic catechols with antiinfluenza activity," Bioorganic \& Medicinal Chemistry, vol. 21, no. 24, pp. 7699-7708, 2013.

[11] B. M. Bizzarri, L. Botta, E. Capecchi et al., "Regioselective IBXmediated synthesis of coumarin derivatives with antioxidant and anti-influenza activities," Journal of Natural Products, vol. 80, no. 12, pp. 3247-3254, 2017.

[12] C. Ehrhardt, E. Hrincius, V. Korte et al., "A polyphenol rich plant extract, CYSTUS052, exerts anti influenza virus activity in cell culture without toxic side effects or the tendency to induce viral resistance," Antiviral Research, vol. 76, no. 1, pp. 38-47, 2007.

[13] M. Haidari, M. Ali, S. Ward Casscells III, and M. Madjid, "Pomegranate (Punica granatum) purified polyphenol extract 
inhibits influenza virus and has a synergistic effect with oseltamivir," Phytomedicine, vol. 16, no. 12, pp. 1127-1136, 2009.

[14] R. Bahramsoltani, H. R. Sodagari, M. H. Farzaei, A. H. Abdolghaffari, M. Gooshe, and N. Rezaei, "The preventive and therapeutic potential of natural polyphenols on influenza," Expert Review of Anti-Infective Therapy, vol. 14, no. 1, pp. 57-80, 2016.

[15] S. Wunderlich, A. Zürcher, and W. Back, "Enrichment of xanthohumol in the brewing process," Molecular Nutrition \& Food Research, vol. 49, no. 9, pp. 874-881, 2005.

[16] S. Possemiers and W. Verstraete, "Oestrogenicity of prenylflavonoids from hops: activation of pro-oestrogens by intestinal bacteria," Environmental Microbiology Reports, vol. 1, no. 2, pp. 100-109, 2009.

[17] C. Schönberger and T. Kostelecky, "125th anniversary review: the role of hops in brewing," Journal of the Institute of Brewing, vol. 117, no. 3, pp. 259-267, 2011.

[18] C. Almaguer, C. Schönberger, M. Gastl, E. K. Arendt, and T. Becker, "Humulus lupulus - a story that begs to be told. A review," Journal of the Institute of Brewing, vol. 120, no. 4, pp. 289-314, 2014.

[19] M. Van Cleemput, K. Cattoor, K. De Bosscher, G. Haegeman, D. De Keukeleire, and A. Heyerick, "Hop (Humulus lupulus)derived bitter acids as multipotent bioactive compounds," Journal of Natural Products, vol. 72, no. 6, pp. 1220-1230, 2009.

[20] P. Zanoli and M. Zavatti, "Pharmacognostic and pharmacological profile of Humulus lupulus L.," Journal of Ethnopharmacology, vol. 116, no. 3, pp. 383-396, 2008.

[21] Committee on Herbal Medicinal Products (HMPC), "Assessment report on Humulus lupulus L., flos," No. EMA/ HMPC/418902/2005, European Medicines Agency (EMA), London, UK, 2014, http://www.ema.europa.eu/docs/en_GB/ document_library/Herbal_-_HMPC_assessment_report/2014/ 08/WC500170935.pdf.

[22] L. R. Chadwick, G. F. Pauli, and N. R. Farnsworth, "The pharmacognosy of Humulus lupulus L. (hops) with an emphasis on estrogenic properties," Phytomedicine, vol. 13, no. 1-2, pp. 119-131, 2006.

[23] M. Karabin, T. Hudcova, L. Jelinek, and P. Dostalek, "Biotransformations and biological activities of hop flavonoids," Biotechnology Advances, vol. 33, no. 6, pp. 1063-1090, 2015.

[24] T. Inui, K. Okumura, H. Matsui, T. Hosoya, and S. Kumazawa, "Effect of harvest time on some in vitro functional properties of hop polyphenols," Food Chemistry, vol. 225, pp. 69-76, 2017.

[25] V. E. Buckwold, R. J. Wilson, A. Nalca et al., "Antiviral activity of hop constituents against a series of DNA and RNA viruses," Antiviral Research, vol. 61, no. 1, pp. 57-62, 2004.

[26] A. Di Sotto, I. Celestino, C. Toniolo et al., "Antiviral and antioxidant activity of a hydroalcoholic extract from Humulus lupulus L.," in 38th SIF National Congress (Italian Society of Pharmacology), Rimini, Italy, October 2016.

[27] A. Di Sotto, M. Vecchiato, L. Abete et al., "Capsicum annuum L. var. Cornetto di Pontecorvo PDO: polyphenolic profile and in vitro biological activities," Journal of Functional Foods, vol. 40, pp. 679-691, 2018.

[28] T. Mosmann, "Rapid colorimetric assay for cellular growth and survival: application to proliferation and cytotoxicity assays," Journal of Immunological Methods, vol. 65, no. 1-2, pp. 55-63, 1983.

[29] L. Nencioni, A. Iuvara, K. Aquilano et al., "Influenza A virus replication is dependent on an antioxidant pathway that involves GSH and Bcl-2," The FASEB Journal, vol. 17, no. 6, pp. 758-760, 2003.

[30] I. Rahman, A. Kode, and S. K. Biswas, “Assay for quantitative determination of glutathione and glutathione disulfide levels using enzymatic recycling method," Nature Protocols, vol. 1, no. 6, pp. 3159-3165, 2006.

[31] D. Di Majo, M. La Guardia, S. Giammanco, L. La Neve, and M. Giammanco, "The antioxidant capacity of red wine in relationship with its polyphenolic constituents," Food Chemistry, vol. 111, no. 1, pp. 45-49, 2008.

[32] A. Di Sotto, F. Durazzi, M. G. Sarpietro, and G. Mazzanti, "Antimutagenic and antioxidant activities of some bioflavours from wine," Food and Chemical Toxicology, vol. 60, pp. 141146, 2013.

[33] J. Peterson and J. Dwyer, “Taxonomic classification helps identify flavonoid-containing foods on a semiquantitative food frequency questionnaire," Journal of the American Dietetic Association, vol. 98, no. 6, pp. 677-685, 1998.

[34] F. C. Önder, M. Ay, and S. D. Sarker, "Comparative study of antioxidant properties and total phenolic content of the extracts of Humulus lupulus L. and quantification of bioactive components by LC-MS/MS and GC-MS," Journal of Agricultural and Food Chemistry, vol. 61, no. 44, pp. 10498-10506, 2013.

[35] S. Segawa, K. Yasui, Y. Takata, T. Kurihara, H. Kaneda, and J. Watari, "Flavonoid glycosides extracted from hop (Humulus lupulus L.) as inhibitors of chemical mediator release from human basophilic KU812 cells," Bioscience, Biotechnology, and Biochemistry, vol. 70, no. 12, pp. 2990-2997, 2006.

[36] P. J. Magalhães, J. S. Vieira, L. M. Gonçalves, J. G. Pacheco, L. F. Guido, and A. A. Barros, "Isolation of phenolic compounds from hop extracts using polyvinylpolypyrrolidone: characterization by high-performance liquid chromatography-diode array detection-electrospray tandem mass spectrometry," Journal of Chromatography A, vol. 1217, no. 19, pp. 3258-3268, 2010.

[37] A. Maietti, V. Brighenti, G. Bonetti et al., "Metabolite profiling of flavonols and in vitro antioxidant activity of young shoots of wild Humulus lupulus L. (hop)," Journal of Pharmaceutical and Biomedical Analysis, vol. 142, pp. 28-34, 2017.

[38] M. Biesaga, A. Wach, M. Donten, J. Maik, and K. Pyrzynska, "Acidic hydrolysis and extraction of natural dyes present in plants and ancient textiles," Chemia Analityczna, vol. 51, pp. 251-265, 2006.

[39] D. Kowalczyk, M. Świeca, J. Cichocka, and U. Gawlik-Dziki, "The phenolic content and antioxidant activity of the aqueous and hydroalcoholic extracts of hops and their pellets," Journal of the Institute of Brewing, vol. 119, no. 3, pp. 103-110, 2013.

[40] F. P. Prencipe, V. Brighenti, M. Rodolfi et al., "Development of a new high-performance liquid chromatography method with diode array and electrospray ionization-mass spectrometry detection for the metabolite fingerprinting of bioactive compounds in Humulus lupulus L," Journal of Chromatography A, vol. 1349, pp. 50-59, 2014.

[41] P. Checconi, R. Sgarbanti, I. Celestino et al., "The environmental pollutant cadmium promotes influenza virus replication in MDCK cells by altering their redox state," International Journal of Molecular Sciences, vol. 14, no. 2, pp. 4148-4162, 2013.

[42] J. Cai, Y. Chen, S. Seth, S. Furukawa, R. W. Compans, and D. P. Jones, "Inhibition of influenza infection by glutathione," Free Radical Biology \& Medicine, vol. 34, no. 7, pp. 928-936, 2003. 
[43] S. Wang, R. Mateos, L. Goya, M. Amigo-Benavent, B. Sarriá, and L. Bravo, "A phenolic extract from grape by-products and its main hydroxybenzoic acids protect Caco- 2 cells against pro-oxidant induced toxicity," Food and Chemical Toxicology, vol. 88, pp. 65-74, 2016.

[44] T. Oda, T. Akaike, T. Hamamoto, F. Suzuki, T. Hirano, and H. Maeda, "Oxygen radicals in influenza-induced pathogenesis and treatment with pyran polymer-conjugated SOD," Science, vol. 244, no. 4907, pp. 974-976, 1989.

[45] S. Pleschka, T. Wolff, C. Ehrhardt et al., "Influenza virus propagation is impaired by inhibition of the Raf/MEK/ERK signalling cascade," Nature Cell Biology, vol. 3, no. 3, pp. 301-305, 2001.

[46] V. Abram, B. Čeh, M. Vidmar et al., "A comparison of antioxidant and antimicrobial activity between hop leaves and hop cones," Industrial Crops and Products, vol. 64, pp. 124-134, 2015.

[47] M. A. Prieto, J. A. Vázquez, and M. A. Murado, "Crocin bleaching antioxidant assay revisited: application to microplate to analyse antioxidant and pro-oxidant activities," Food Chemistry, vol. 167, pp. 299-310, 2015.

[48] T. Ak and I. Gülçin, "Antioxidant and radical scavenging properties of curcumin," Chemico-Biological Interactions, vol. 174, no. 1, pp. 27-37, 2008.

[49] A. Ayala, M. F. Muñoz, and S. Argüelles, "Lipid peroxidation: production, metabolism, and signaling mechanisms of malondialdehyde and 4-hydroxy-2-nonenal," Oxidative Medicine and Cellular Longevity, vol. 2014, Article ID 360438, 31 pages, 2014.

[50] H. E. Seifried, D. E. Anderson, E. I. Fisher, and J. A. Milner, “A review of the interaction among dietary antioxidants and reactive oxygen species," The Journal of Nutritional Biochemistry, vol. 18, no. 9, pp. 567-579, 2007.

[51] A. Bartmańska, T. Tronina, J. Popłoński, and E. Huszcza, “Biotransformations of prenylated hop flavonoids for drug discovery and production," Current Drug Metabolism, vol. 14, no. 10, pp. 1083-1097, 2013.

[52] P. Mladěnka, K. Macáková, T. Filipský et al., "In vitro analysis of iron chelating activity of flavonoids," Journal of Inorganic Biochemistry, vol. 105, no. 5, pp. 693-701, 2011.

[53] D. Genovese, C. Conti, P. Tomao et al., "Effect of chloro-, cyano-, and amidino-substituted flavanoids on enterovirus infection in vitro," Antiviral Research, vol. 27, no. 1-2, pp. 123-136, 1995.

[54] A. L. Salvati, A. De Dominicis, S. Tait, A. Canitano, A. Lahm, and L. Fiore, "Mechanism of action at the molecular level of the antiviral drug $3(2 \mathrm{H})$-isoflavene against type 2 poliovirus," Antimicrobial Agents and Chemotherapy, vol. 48, no. 6, pp. 2233-2243, 2004.

[55] Q. Wang, Z. H. Ding, J. K. Liu, and Y. T. Zheng, "Xanthohumol, a novel anti-HIV-1 agent purified from hops Humulus lupulus," Antiviral Research, vol. 64, no. 3, pp. 189-194, 2004.

[56] H. J. Jeong, Y. B. Ryu, S. J. Park et al., "Neuraminidase inhibitory activities of flavonols isolated from Rhodiola rosea roots and their in vitro anti-influenza viral activities," Bioorganic \& Medicinal Chemistry, vol. 17, no. 19, pp. 6816-6823, 2009.

[57] Z. F. Yang, L. P. Bai, W. B. Huang et al., "Comparison of in vitro antiviral activity of tea polyphenols against influenza A and B viruses and structure-activity relationship analysis," Fitoterapia, vol. 93, pp. 47-53, 2014.
[58] L. Chen, J. Dou, Z. Su et al., "Synergistic activity of baicalein with ribavirin against influenza A (H1N1) virus infections in cell culture and in mice," Antiviral Research, vol. 91, no. 3, pp. 314-320, 2011.

[59] V. M. Savov, A. S. Galabov, L. P. Tantcheva et al., "Effects of rutin and quercetin on monooxygenase activities in experimental influenza virus infection," Experimental and Toxicologic Pathology, vol. 58, no. 1, pp. 59-64, 2006.

[60] A. K. Ibrahim, A. I. Youssef, A. S. Arafa, and S. A. Ahmed, "Anti-H5N1 virus flavonoids from Capparis sinaica Veill," Natural Product Research, vol. 27, no. 22, pp. 2149-2153, 2013.

[61] A. L. Liu, H. D. Wang, S. M. Lee, Y. T. Wang, and G. H. du, "Structure-activity relationship of flavonoids as influenza virus neuraminidase inhibitors and their in vitro anti-viral activities," Bioorganic \& Medicinal Chemistry, vol. 16, no. 15, pp. 7141-7147, 2008.

[62] C. H. Lin, T. T. Chang, M. F. Sun et al., "Potent inhibitor design against $\mathrm{H} 1 \mathrm{~N} 1$ swine influenza: structure-based and molecular dynamics analysis for M2 inhibitors from traditional Chinese medicine database," Journal of Biomolecular Structure and Dynamics, vol. 28, no. 4, pp. 471-482, 2011.

[63] J. H. Lee, M. Oh, J. Seok et al., "Antiviral effects of black raspberry (Rubus coreanus) seed and its gallic acid against influenza virus infection," Viruses, vol. 8, no. 6, pp. 1-12, 2016. 


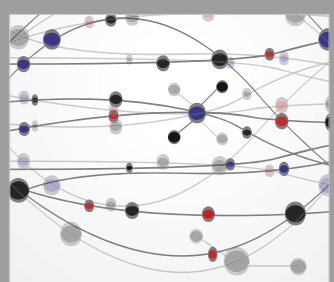

The Scientific World Journal
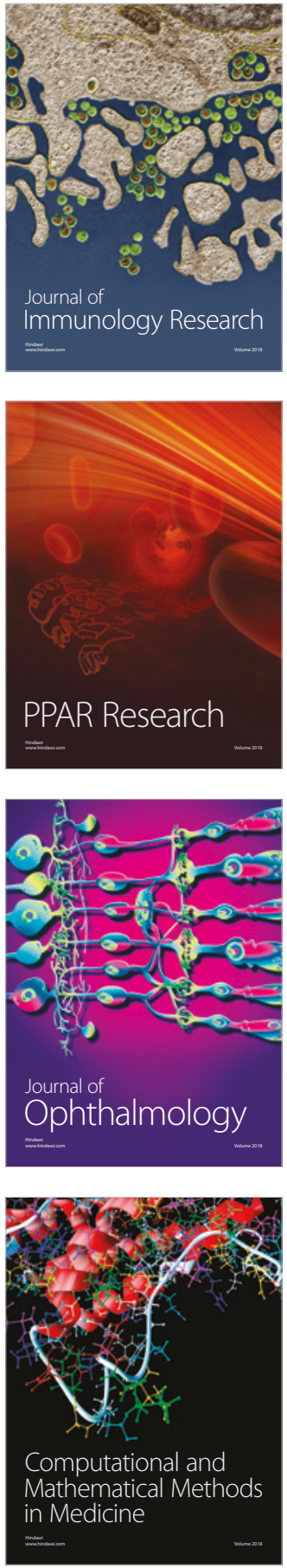

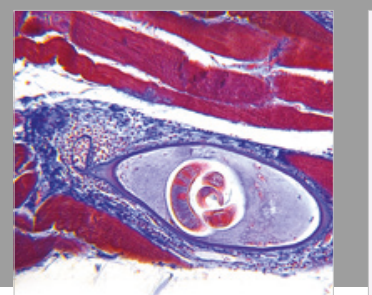

Gastroenterology Research and Practice

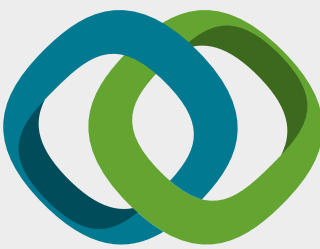

\section{Hindawi}

Submit your manuscripts at

www.hindawi.com
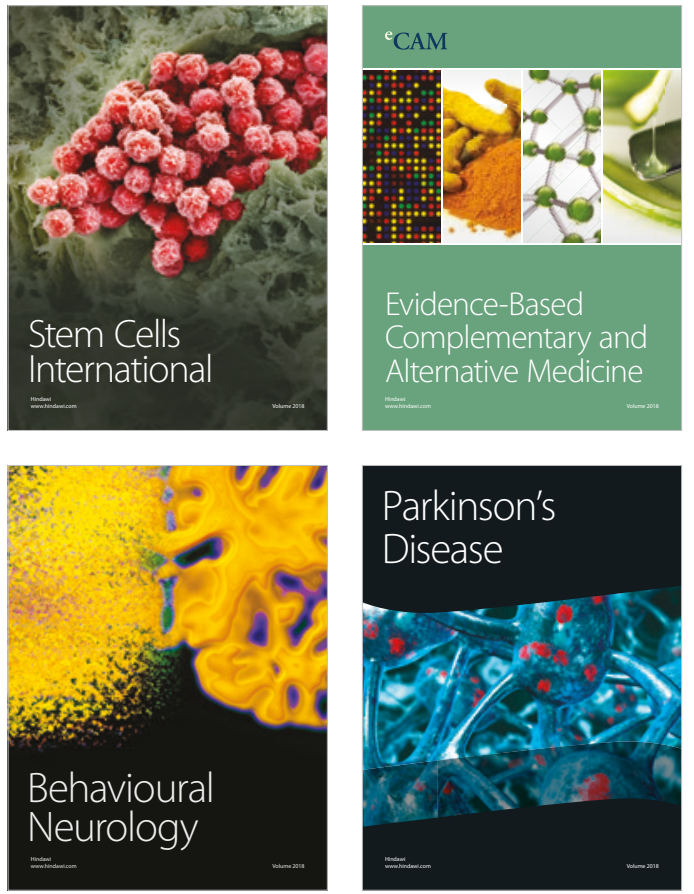

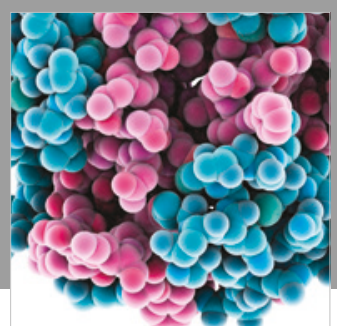

ournal of

Diabetes Research

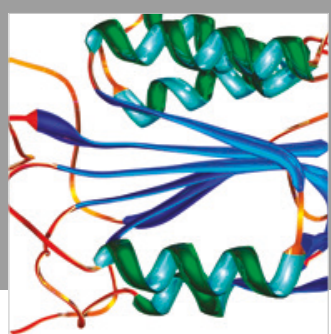

Disease Markers
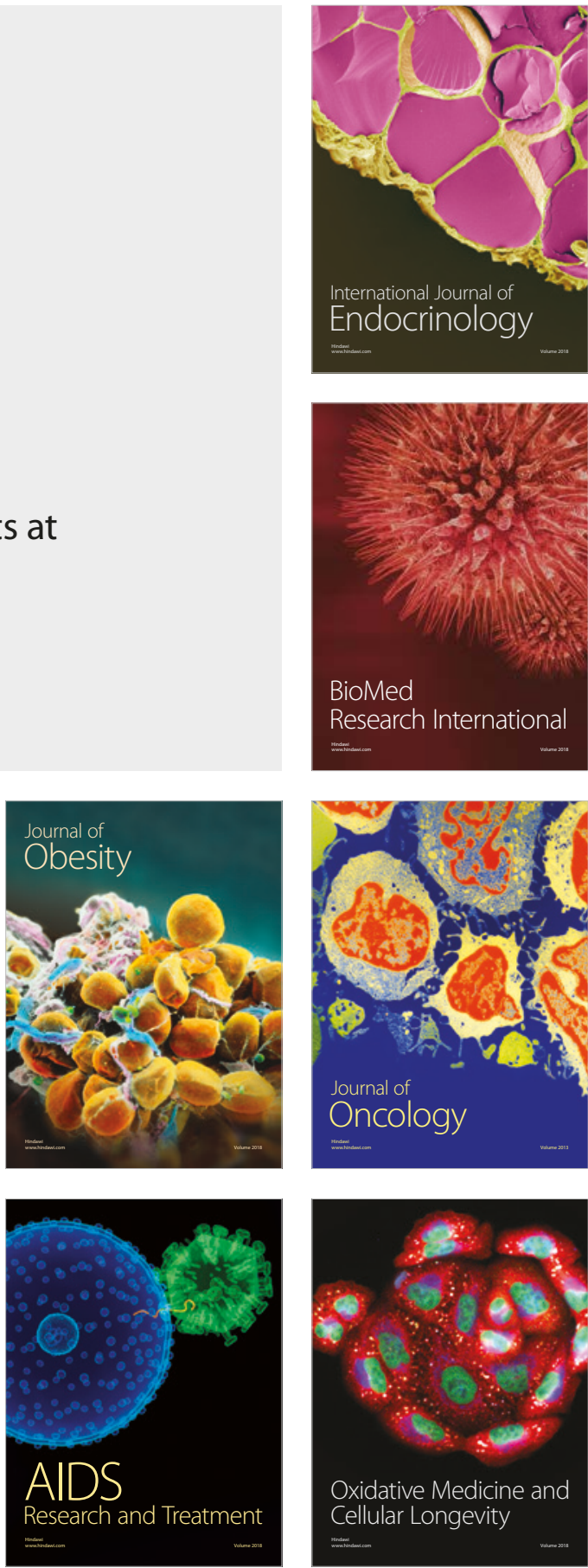